\title{
Divina juventud: La Iglesia católica y las juventudes en América Latina y Costa Rica durante la Guerra Fría (1965-1989)
}

\section{Divine Youth: The Catholic Church and Youth in Latin America and Costa Rica during the Cold War (1965-1989)}

\section{Randall Chaves Zamora*}

\begin{abstract}
Resumen: La Iglesia católica y las juventudes protagonizaron muchos de los escenarios globales durante la Guerra Fría. Las páginas siguientes conjugan ambas temáticas, para analizar el interés transnacional del catolicismo por las juventudes entre las décadas de 1960 y 1980. Para hacerlo, inicialmente se analizan los discursos oficiales de esta institución global y se estudia el concepto político de juventud que ensayó esa religión durante el período en estudio. Posteriormente, se analiza cómo se tradujo el interés por la juventud en América Latina y se presentan las estrategias de las jerarquías católicas para agrupar a las juventudes. Al final, se establece una comparación con el caso costarricense, donde los discursos globales y latinoamericanos sobre las juventudes católicas fueron apropiados y adaptados a un país que buscaba representar a sus jóvenes como un sector aislado de la región centroamericana.
\end{abstract}

Palabras claves: Guerra Fría; juventud; religión; catolicismo; historia; América Latina; Centroamérica; Costa Rica.

Abstract: The Catholic Church and youth were protagonists on the global stage during the Cold War. The following pages look at both agents in an effort to study

Fecha de recepción: 09/12/2019 - Fecha de aceptación: 19/02/2020

* Costarricense. Estudiante del Doctorado en Historia y Máster en Historia por la Universidad de Costa Rica (UCR), Costa Rica. Profesor de la Escuela de Historia e investigador del Centro de Investigaciones Históricas de América Central (CIHAC) de la Universidad de Costa Rica (UCR), Costa Rica. Correo electrónico: randall.chaveszamora@ucr.ac.cr. Actualmente investiga la intelectualidad costarricense durante la Guerra Fría. Este artículo es resultado del Proyecto de Investigación B9721, financiado por la Vicerrectoría de Investigación de la UCR y desarrollado en el Proyecto de Investigación en Estudios Latinoamericanos Avanzados (CALAS) del CIHAC.

El autor agradece profundamente la colaboración de David Díaz Arias, Pablo Durand Barquerizo, Miriam Kopp, Marcela Otárola Guerara, Mariela Rojas Castillo y los comentarios, sugerencias y observaciones de las personas que dictaminaron de este artículo. 
the transnational interest in young people by the Catholic Church between the 1960s and 1980s. To do so, the paper analyzes the official discourse of this global institution and the political concept of youth that shaped the religion during the period in question. Subsequently, it examines how the interest in the Latin American youth was pursued and presents strategies on how the Catholic hierarchies organized these youth groups. Finally, it establishes a comparison with the Costa Rican case, where the global and Latin American discourses on Catholic youth were adapted by a country that sought to represent its youth as an isolated sector of the Central American region.

Keywords: Cold War; youth; religion; Catholicism; Latin American history; Central America; Costa Rica.

\section{Introducción}

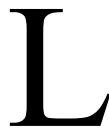

a agenda diplomática era apretada y el viaje era corto y ambicioso. $\mathrm{Su}$ visita era esperada por millones y millones de personas de toda la región centroamericana. En los ocho días que abarcaban del 2 al 10 de marzo de 1983, el papa Juan Pablo II, con apenas un lustro en el pontificado (1978-2005), visitaría ocho países: Belice, Haití y la América Central de la Guerra Fría, que atravesaba los más álgidos conflictos militares y políticos del siglo XX. Durante sus primeras jornadas de trabajo en la región, cada noche el papa encontraría un remanso de tranquilidad entre la guerra, la pobreza y la violencia: la mítica paz costarricense lo recibiría tras sus visitas a Nicaragua y Panamá y allí, en territorio desmilitarizado, gobernado por políticos opuestos al gobierno revolucionario nicaragüense y que empezaban a discutir su «neutralidad» frente al conflicto centroamericano, él podría dormir seguro. ${ }^{1}$ En términos oficiales, el papa llevaría el evangelio hasta una región pobre y en guerra, pero en términos políticos, el diplomático anticomunista buscaría poner fin a los enfrentamientos armados que caracterizaban a El Salvador, Guatemala y Nicaragua. La atención de la prensa durante los primeros días se había centrado principalmente en Nicaragua, donde la Iglesia católica había jugado un rol protagónico desde el inicio de la Revolución Sandinista. ${ }^{2}$

1 Sofía Cortés Sequeira, «Izquierda y neutralidad perpetua (1983-1984)», en: Ahí me van a matar. Cultura, violencia y Guerra Fría en Costa Rica (1970-190), ed. por Iván Molina Jiménez y David Díaz Arias (San José, Costa Rica: EUNED, 2018), 127-163; David Díaz Arias, «Historia de un viraje: la 'neutralidad perpetua', la administración Monge Álvarez y la desigual construcción de la opinión pública en Costa Rica, 1982-1986», en: Historia de las desigualdades sociales en América Central. Una visión interdisciplinaria, siglos XVII-XXI, (ed.) Ronny Viales Hurtado y David Díaz Arias (San José, Costa Rica: CIHAC, 2016), 591-611.

2 Philip J. Williams, The Catholic Church and Politics in Nicaragua and Costa Rica (Nueva York: Palgrave Macmillan, 1989), 65-96. 
La estrechez de su agenda y la importancia de su visita hacía que cada actividad estuviera meticulosamente planeada. Cada discurso debía estar previamente escrito en español, y por los altos dispositivos de seguridad, los protagonistas de cada encuentro debían ser cuidadosamente seleccionados. Así, una edición especial en español de L'Observatore Romano, el periódico del Vaticano, informó que entre el 2 y el 3 de marzo de 1983, fueron solamente tres selectos grupos de la sociedad costarricense quienes pudieron compartir con el papa: los obispos, quienes se reunieron con él durante la noche del 2 de marzo, religiosos y religiosas de distintas órdenes monásticas, que se reunieron durante la mañana del día siguiente para rezar con él en la Catedral Metropolitana de San José y la juventud costarricense, convocada la tarde del 3 de marzo para una reunión masiva con el líder global de la Iglesia católica en el Estadio Nacional. ${ }^{3}$

Allí, una muchedumbre juvenil de cuarenta mil personas saludó eufóricamente al papa y todo fue narrado por el mismo rotativo religioso, que más tarde sería comercializado en toda Centroamérica. Jóvenes de todo el país escucharon el discurso del líder, quien con sus palabras, dejó el destino del istmo en sus manos al concluir: «El futuro de América Central estará en vuestras manos; lo está ya en parte. Procurad ser dignos de tamaña responsabilidad». ${ }^{4}$ Guiado por esta idea, el papa insistió en que eran solamente las personas jóvenes quienes podrían construir una «nueva Centroamérica»; el futuro de la región, con la juventud como portadora del cambio, sustituiría la violencia de la guerra por «la civilización del amor». Así, él mismo advirtió a la multitud juvenil:

No basta, efectivamente, contemplar los tantos males que descubrís en derredor vuestro, o lamentarlos pasivamente. No basta tampoco criticarlos. No aportaría solución alguna declararse impotentes o vencidos ante el mal y dejarse llevar por la desesperanza. No, no es ése el camino de solución. Cristo os llama a comprometeros en favor del bien, de la destrucción del egoísmo y del pecado en todas sus formas [...] Sí, vosotros, amadísimos jóvenes, tenéis la grave responsabilidad de romper la cadena del odio que produce odio, y de la violencia que engendra violencia. Habéis de crear un mundo mejor que el de vuestros antepasados. Si no lo hacéis, la sangre seguirá corriendo; y mañana, las lágrimas darán testimonio del dolor de vuestros hijos. Os invito pues como hermano y amigo, a luchar con toda la energía de vuestra juventud contra el odio y la violencia, hasta que se restablezca el amor y la paz en vuestras naciones. Vosotros estáis llamados a enseñar a los demás la lección del amor, del amor cristiano, que es al mismo tiempo humano y divino. Estáis llamados a sustituir el odio con la civilización del amor. Esto lo podréis realizar por el camino espléndido de la amistad auténtica, de la que lleva siempre a lo más alto y noble; de la amistad que aprendéis de Cristo, que ha de ser siempre

3 L'Observatore Romano, «Itinerario apostólico de Juan Pablo II por América Central, 2-10 marzo 1983», mayo de 1983, 4 y 5.

4 Juan Pablo II, «Discurso del papa a los jóvenes en el Estadio Nacional», L'Observatore Romano, mayo de 1983,15 y 16. 
vuestro modelo y gran amigo. Y rechazando con gallardía a cuantos recurren al odio y sus manifestaciones como instrumentos para forjar una nueva sociedad. ${ }^{5}$

La reunión de más de tres horas evidenció el interés «humano y divino» que los jerarcas de la Iglesia católica tenían sobre las juventudes, pero, ¿por qué, en medio de un viaje diplomático por una región en crisis política y militar, el papa había solicitado reunirse públicamente con un sector de la población tan heterogéneo como la juventud costarricense? ¿De dónde venía su interés por dirigirle un discurso a esas personas jóvenes? ¿Representaba este uno de los intereses transnacionales de la Iglesia católica? Ciertamente, este no era un tema novedoso para el ámbito oficial católico. Como el mismo Juan Pablo II lo mencionaba con insistencia en su paso por Costa Rica, la preocupación institucional por la juventud era central desde el Concilio Vaticano II (1962-1965), cuando la Iglesia había reformado su institucionalidad religiosa y dirigía su mensaje concluyente a la juventud, heredera del futuro y de la juventud de Cristo. ${ }^{6}$

$\mathrm{Al}$ ser una institución con jerarquías eclesiásticas en todo el planeta, el interés de la Iglesia por la juventud buscó extenderse y adaptarse a distintos contextos políticos. En el caso de América Latina, ese interés católico por la juventud fue replicado en las conferencias del Consejo Episcopal Latinoamericano (CELAM) desarrolladas en Medellín durante 1968 y una década más tarde en Puebla, cuando los obispos latinoamericanos asumieron una «opción preferencial por los jóvenes», que implicaba la creación de grupos católicos exclusivos para jóvenes en cada una de las comunidades latinoamericanas. ${ }^{7}$ Consecuentemente, fue durante la década de 1980 cuando el catolicismo buscó reconfigurar el protagonismo de las personas jóvenes en la región. La tremenda insistencia en este asunto se materializó tres años después de la visita del papa a Centroamérica, cuando él mismo inventó y celebró la primera Jornada Mundial de la Juventud en Roma, un encuentro global de jóvenes católicos que tendría, y sigue teniendo, sedes itinerantes alrededor del mundo. En esa década crecerían las iniciativas de la Iglesia en las que muchachos y muchachas podrían formar parte y liderar movimientos religiosos protagonizados por la juventud.

Por todo lo anterior, este artículo utiliza discursos y documentos oficiales de la Iglesia católica en América Latina y Costa Rica para analizar la creciente preocupación global del catolicismo sobre las personas jóvenes hacia la década de 1980. Para ello, inicialmente se estudia el concepto político de juventud

5 Ibíd.

6 Pablo VI, «Mensaje del Concilio Vaticano II a los jóvenes», Vatican, 7 de diciembre de 1965. Todos los discursos oficiales citados en este artículo pueden consultarse Vatican, la página web oficial de la Ciudad del Vaticano, http://www.vatican.va/holy_father/index_sp.htm.

7 Consejo Episcopal Latinoamericano, III Confrerencia General del Episcopado Latinoamericano. Documento de Puebla (México: Secretariado General del Consejo Episcopal Latinoamericano, 1978), véase capítulo II. 
que moldeó esta organización transnacional y los mecanismos creados por ella para agrupar a las juventudes católicas de todo el mundo y, particularmente, de América Latina. Finalmente, se realiza un acercamiento al caso de la juventud latinoamericana en general y costarricense en particular, para explicar la proliferación de las organizaciones de la juventud y la forma en que estas intentaron configurar identidades juveniles desradicalizadas durante la última década de la Guerra Fría.

Aunque se conoce el valor de los documentos que produjeron las organizaciones juveniles de la Iglesia católica y aunque se reconoce la importancia de conocer las visiones de sus protagonistas, este artículo es un primer acercamiento a las discursividades y perspectivas sobre la juventud de la Iglesia católica en América Latina y busca presentar una visión preliminar sobre esta temática en Costa Rica. Por lo tanto, para realizar esta tarea inicial se recurrió a documentos oficiales y discursos sobre la juventud que Juan Pablo II pronunció durante la primera y segunda década de su pontificado, con el fin de identificar las principales definiciones y preocupaciones que el líder global de la Iglesia católica atribuyó a la juventud de todo el mundo. También, se revisan y analizan los documentos de las conferencias del CELAM celebradas en Medellín y Puebla, donde líderes de Latinoamérica evidenciaron su interés por las personas jóvenes de la región. Ambos documentos permitirán comprender los orígenes de esta inclinación eclesiástica por la juventud, así como la orientación política de esa inclinación, las iniciativas, las acciones implementadas y el objetivo que buscó la institución religiosa. En la tercera parte de este artículo, se estudian los documentos y discursos oficiales de la Iglesia en Costa Rica, para comprender cómo se desarrolló este proyecto eclesial en un país conocido en la región por la ausencia del conflicto armado y por la desradicaliazación política de su juventud.

\section{La Iglesia católica y las juventudes en la historiografía}

Si bien, el concepto de juventud ha sido objeto de numerosos análisis desde las ciencias sociales, ${ }^{8}$ sería imposible enumerar la sobresaliente cantidad de estudios sobre las organizaciones juveniles de todo tipo que surgieron en América Latina, Estados Unidos y Europa durante todo el siglo XX. Mucho más prolífico ha sido el campo de estudios historiográficos dedicado al análisis de los movimientos estudiantiles en todo el mundo, preocupado por abordar una de las formas más comunes de comprender a las juventudes del pasado. Esto porque desde finales de la década de 1960, las juventudes del mundo entero transitaron

8 José Antonio Pérez Islas, «Juventud: un concepto en disputa», en: Teorías sobre la juventud. Las miradas de los clásicos, (coord.) José Antonio Pérez Islas, Mónica Valdéz González y María Herlinda Suárez Zozaya (México, D.F.: Universidad Nacional Autónoma de México, 2008), 9-33; Juan Carlos Revilla Castro, «La construcción discursiva de la juventud: lo general y lo particular», Papers, n. ${ }^{\circ}$ 63-64 (2001): 103-122, http://dx.doi.org/10.5565/rev/papers/v63n0.1209. 
de las calles y otros espacios de protesta hacia el protagonismo de innumerables estudios sobre el crecimiento demográfico de las personas jóvenes, sus prácticas culturales, sus principales productos de consumo, sus reivindicaciones y el estudio de la inagotable cantidad de legislaciones que trataron de normar y desradicalizar las identidades juveniles. ${ }^{9}$

Así, aunque todo apunta a que el papel de la Iglesia católica en este último tema fue central y aunque se conocen los importantes estudios sobre la Iglesia católica costarricense preocupados por esa institución durante los siglos XIX y XX y su sobresaliente papel en la política costarricense, ${ }^{10}$ todavía no existen trabajos sobre el rol jugado por la institución en la definición de temáticas juveniles o su impacto en la creación de un concepto de juventud específico en América Latina y Costa Rica. Desde la teología y la política internacional, una tendencia de estudios se ha preocupado por analizar el rol transnacional de Juan Pablo II en el fin de la Guerra Fría. Aunque algunos lo hacen desde un expreso compromiso con el catolicismo y con la política estadounidense, esos trabajos son valiosos al demostrar que, durante esta coyuntura global, Juan Pablo II no solamente fue un líder espiritual, sino que entendió y capitalizó la naturaleza política de su cargo y eso lo convirtió en una de las figuras políticas más influyentes del mundo. ${ }^{11}$

Finalmente, algunos trabajos académicos se han preocupado por el estudio de la Iglesia latinoamericana en relación a contextos de cambio institucional como los referenciados de Medellín y Puebla. ${ }^{12}$ Este artículo rescata tales visio-

9 Esta discusión puede verse ampliamente en: Randall Chaves Zamora, Fuimos jóvenes: historia y memoria de las manifestaciones estudiantiles contra ALCOA en Costa Rica, (1968-2018) (Tesis de Maestría Académica en Historia, Universidad de Costa Rica, 2018), 9-51.

10 Cfr. Miguel Picado Gatjens, Secretos de un acuerdo: Monseñor Sanabria y Manuel Mora, junio de 1943 (San José: Editorial de la Universidad Estatal a Distancia, 2013); Miguel Picado Gatjens, La Iglesia costarricense: entre Dios y el César (San José: Departamento Ecuménico de Investigaciones, 1989); José Daniel Gil Zúñiga, «Un mito de la sociedad costarricense: el culto a la Virgen de los Ángeles (1824-1935)», Revista de Historia, n. ${ }^{\circ} 11$ (julio-diciembre, 1985): 47-129, https://www.revistas.una.ac.cr/index.php/historia/article/view/3184.; Iván Molina Jiménez, «Catolicismo y comunismo en Costa Rica (1931-1940)», Desacatos, n. 22 (2006): 157-172, http://desacatos.ciesas.edu.mx/index.php/Desacatos/article/view/625.; José Aurelio Sandí Morales, «La participación de la Iglesia católica en el control del espacio en medio de la creación de un país llamado Costa Rica, 1850-1920», Revista de Historia, n. ${ }^{\circ} 63-64$ (enero-diciembre, 2011): 53-99, https://www.revistas.una.ac.cr/index.php/historia/article/view/4583; Claudio Vargas Arias, El liberalismo, la Iglesia y el Estado en Costa Rica (San José: Ediciones Guayacán, 1987); Carmela Velázquez Bonilla, «La Diócesis de Nicaragua y Costa Rica: su conformación y sus conflictos, 1531-1850», Revista de Historia, n. ${ }^{\circ}$ 49-50 (enero-diciembre, 2004): 245-286, https://www.revistas.una.ac.cr/index. $\mathrm{php} /$ historia/article/view/1788.

11 Chester Gillis, Political Papacy: John Paul II, Benedict XVI, and Their Influence (Nueva York: Routledge, 2006); Paul Kengor, A Pope and a President: John Paul II, Ronald Reagan, and the Extraordinary Untold Story of the 20th Century (Wilmington: Intercollegiate Studies Institute, 2017); Paul Kengor y Robert Orlando, The Divine Plan: John Paul II, Ronald Reagan, and the Dramatic End of the Cold War (Wilmington: Intercollegiate Studies Institute, 2019); Michael Hayes y Gerald O'Collins, The legacy of John Paul II (Nueva York: Continuum International Publishing Group, 2008); Malachi Martin, The Keys of This Blood: Pope John Paul II Versus Russia and the West for Control of the New World Order (Nueva York: A Touchstone Book, 1991).

12 Alejandro Goic, «Opción por los jóvenes: las visiones de Medellín a Puebla. Visiones de la iglesia hoy», en: La juventud latinoamericana en los procesos de globalización. Opción por los jóvenes, (ed.) Peter 
nes, pero al presentar una visión crítica de la acción y el discurso de la Iglesia en relación con la juventud, se aparta del compromiso religioso que muchos de esos autores y autoras manifiestan tácita o explícitamente en relación con las acciones y discursos de las jerarquías católicas. Así, este no es un análisis del contenido teológico de los discursos de una jerarquía religiosa, sino un trabajo historiográfico que, tal y como lo han hecho otros estudios para el caso de México, ${ }^{13} \mathrm{Colom}-$ bia, ${ }^{14}$ Argentina y otros países latinoamericanos durante la Guerra Fría, ${ }^{15}$ estudia críticamente la dimensión política de los discursos religiosos y se preocupa por explorar sus alcances en la construcción de conceptos y organizaciones juveniles mediadas por el poder eclesiástico.

Por estas razones, este estudio comprende a la juventud como una identidad político-cultural cargada de agencia, pero también, de condicionantes impuestos por instituciones con autoridad moral y política. Al comprender así a la juventud, este artículo se aparta de las visiones tradicionales que han valorado este concepto como una transición hacia la vida adulta, como una etapa determinada por la escolarización y la dependencia económica; ${ }^{16}$ pero al apartarse de estas visiones, este artículo no desestima tales perspectivas, sino que busca comprender el concepto de juventud en su dimensión más plural: al tomar en cuenta el sistema educativo y la autoridad patriarcal y económica, pero al prestar mayor atención a la existencia de una agencia condicionada por las imposiciones morales del catolicismo, se busca analizar el concepto de una juventud desradicalizada que fue moldeado por la institución más importante de América Latina durante el período en estudio.

Hunermann y Margit Eckholt (Buenos Aires: Facultad Latinoamericana de Ciencias Sociales, 1998), $77-$ 96; Carmen José Alejos Grau, "América Latina en el siglo XX: religión y política», Studia et Documenta: rivista dell'Istituto Storico San Josemaría Escrivá, n. ${ }^{\circ} 11$ (2017): 19-47, https://www.isje.org/es/ studia-et-documenta-3/numeros-publicados/vol-11-2017/.

13 Mónica Alcántara Navarro, «El Consejo Hispanoamericano de Estudiantes (1979-1980). La juventud católica intransigente en la Guerra Fría», Páginas. Revista Digital de la Escuela de Historia, 11, n. ${ }^{\circ} 25$ (2019): 50-60, http://hdl.handle.net/2133/15038.

14 Óscar Calvo Isaza y Mayra Parra Salazar, Medellín (rojo) 1968 (Bogotá: Editorial Planeta, 2012); Marisol Acosta Franco, «Jóvenes de Medellín, nuevos actores sociales, 1960-1970», Pensar Historia. Revista de Estudiantes de Historia, n. $^{\circ} 4$ (enero-junio, 2014): 21-36, disponible en: http://bibliotecadigital.udea.edu. co/bitstream/10495/6119/1/AcostaYirla_2014_JovenesMedellinActores.pdf.

15 Juan Eduardo Bonnin, Iglesia y democracia. Táctica y estrategia en el discurso de la Conferencia Episcopal Argentina (1981- 1990) (Berlín: Editorial Académica Española, 2011); Juan Eduardo Bonnin, Discurso político y discurso religioso en América Latina. Leyendo los borradores de Medellín (1968) (Buenos Aires: Santiago Arcos Editor, 2013); Juan Eduardo Bonnin, «Las voces de la Teología de la Liberación en los borradores de los Documentos Finales de Medellín (1968)», Bocadesapo. Revista de Arte, Literatura y Pensamiento, 12, n. ${ }^{\circ} 10$ (2011): 16-21, http://hdl.handle.net/11336/5908.; Juan Eduardo Bonnin, «Dinámicas de la voz y producción de legibilidad en los Documentos Finales de Medellín (1968). Un análisis genético-discursivo», Revista Latinoamericana de Estudios del Discurso, 10, n. 2 (2010): 7-28, http:// dx.doi.org/10.35956/v.10.n2.2010.p.7-28.

16 Cfr. Mario Margulis (ed.), La juventud es más que una palabra (Buenos Aires: Editorial Biblos, 2008), 13-30; Revilla Castro, 103-122. 
Es importante anotar que para las décadas de 1970 y 1980 , y a pesar de que el auge de las iglesias protestantes empezaba a reconfigurar la geografía religiosa de la región, ${ }^{17}$ la Iglesia católica no solamente era la denominación más importante de América Latina, sino que su población sobresalía como la más católica del planeta: quienes se declaraban católicos oscilaban entre un noventa y cinco y ochenta por ciento del total de habitantes entre ambas décadas. ${ }^{18}$ Si se acepta un dato como este y si se toma en cuenta el innegable impacto cultural de la Iglesia católica en las identidades de toda la región, es claro que los discursos y acciones emprendidas por el catolicismo, en un tema como el de la juventud, moldearon las identidades juveniles de millones de personas y configuraron muchos de los discursos dominantes con que este sector de la población del pasado reciente de la región fue analizado y valorado.

\section{Jóvenes del mundo entero: la juventud global de la Iglesia católica}

La reunión de Juan Pablo II con la juventud costarricense en su visita a Centroamérica no era novedosa ni excepcional. Por el contrario, este se trataba de un interés global de la Iglesia católica, inaugurado dos décadas antes y que había sido compartido, aunque con menor intensidad, por los antecesores del pontífice. Así, desde que inició su liderazgo, las personas jóvenes eran parte de su agenda y, constantemente, mantuvo reuniones con ellas en distintos lugares del mundo, donde les dedicó decenas de discursos. ¿Pero cuál fue el momento de partida de esta preocupación religiosa y sus actores iniciales?

Indudablemente, uno de los momentos más importantes y de mayores transformaciones para la Iglesia católica durante el siglo XX fue el Concilio Vaticano II; este inició en 1962 y desde entonces, tres papas habían antecedido a Juan Pablo II en el liderazgo de la Iglesia. Las investigaciones históricas preocupadas por la Iglesia católica en la América Latina de la Guerra Fría concuerdan en afirmar que el Concilio no solamente respondía a una necesaria reforma en medio de un mundo profundamente convulso, sino que modificó las bases de la institución y causó un cisma entre las jerarquías del mundo católico. Las reformas permitían que los sacerdotes dejaran de realizar las ceremonias religiosas de espaldas a las personas que asistían a ellas y sustituyeron el uso ritual del latín por la diversidad de idiomas de quienes profesaban el catolicismo en el mundo

17 Heinrich Wilhelm Schäfer, «Transformaciones de la praxis religiosa de actores no-católicos en relación con la violencia. Guatemala y Nicaragua, 1980 a 2015», en: ¿Cuándo pasará el temblor?: Crisis, violencia y paz en la América Latina Contemporánea, (ed.) David Díaz Arias y Christine Hatzky (San José: Centro de Investigaciones Históricas de América Central, 2019), 175-185; Heinrich Wilhelm Schäfer, Protestantismo y crisis social en América Central (San José: Departamento Ecuménico de Investigaciones, 1992).

18 José Orlandis Rovira, «Consideraciones sobre la evolución estadística de la Iglesia en el último cuarto del siglo XX», Anuario de Historia de la Iglesia, n. ${ }^{\circ} 2$ (2003): 181-200, http://hdl.handle.net/10171/9355; Rodolfo de Roux López, «Los inciertos parajes de una nueva geografía religiosa en América Latina», L'ordinaire latino-américain, n. ${ }^{\circ}$ 200-201 (2005): 61-70. 
entero. ${ }^{19}$ Otras investigaciones afirman que a partir de esta reunión, el catolicismo de Roma experimentó una «apertura» a la modernidad, al discutir temas centrales como el marxismo y realidad política del Tercer Mundo. ${ }^{20}$

Ese tremendo, aunque tardío interés de la jerarquía católica por discutir temáticas que hacia los albores de la década de 1960 podían ser consideradas vanguardistas, bien puede comprenderse si se toman en cuenta contextos latinoamericanos como el triunfo de la Revolución cubana, que se extendió desde 1953 y hasta 1959, reconfigurando la política y los discursos anticomunistas en el mundo entero, ${ }^{21}$ provocando un ascenso de los regímenes dictatoriales y autoritarios en la mayor cantidad de países de América Latina y una consecuente reacción conservadora en la que Juan Pablo II jugó un papel de primer orden. Investigaciones recientes afirman que el Concilio Vaticano II implantó un «nuevo paradigma» y contribuyó al surgimiento de preocupaciones de la élite religiosa por temáticas centrales en la región como el hambre, la guerra, la extrema pobreza, las libertades cívicas, el multiculturalismo y la «problemática» juvenil. Al hacer esa afirmación, estos trabajos establecen vínculos directos entre el Concilio, la reunión de obispos latinoamericanos en Medellín y el surgimiento de movimientos tan importantes como el de las teologías latinoamericanistas - del que Teología de la Liberación fue su máximo exponente-, las comunidades eclesiales de base y las pastorales juveniles, que eran producto de reflexionar sobre los documentos conciliares y sobre cómo aplicarlos en América Latina. ${ }^{22}$

Siguiendo a Émile Poulat -un reconocido historiador de la Iglesia católica en Francia-, Juan Eduardo Bonnin afirma que, desde las primeras décadas del siglo XX, América Latina había sido escenario del surgimiento de un «catolicismo integral», que lejos de renegar de la modernidad de las sociedades, se introducía de lleno en ella para generar cambios y transformaciones. Según Bonnin, desde esa perspectiva se puede comprender la intervención eclesiástica en algunos ámbitos políticos como «sindicatos, universidades, empresas y partidos políticos»; no obstante, las ideas conciliares de la década de 1960, adaptadas más tarde por la Iglesia latinoamericana, generarían una escalada conservadora durante el papado de Juan Pablo II, en cuyo contexto fueron censurados y sancionados los representantes más sobresalientes de la Teología de la Liberación, identificados con el espíritu «libertario» $\mathrm{y}$ «desafiante de las jerarquías» con el que se presentaba el Concilio

19 Álvaro Acevedo Tarazona y Adrián Delgado Díaz, «Teología de la liberación y pastoral de la Liberación: entre la solidaridad y la insurgencia», Anuario de Historia Regional y de las Fronteras, 17, n. ${ }^{\circ} 1$ (enero-junio, 2012): 245-268, https://revistas.uis.edu.co/index.php/anuariohistoria/article/view/2723.

20 Nerio Neirotti y Matías Mattalini, «La Iglesia católica en América Latina», en: Atlas histórico de América Latina y el Caribe: aportes para la descolonización pedagógica y cultural. Tomo III: América Latina en el siglo XXI: la edad de los derechos en la patria de la justicia, (ed.) Ana Jaramillo (Lanús: Editorial de la Universidad Nacional de Lanús, 2017), 209.

21 Rafael Rojas, Historia mínima de la Revolución cubana (México: El Colegio de México, 2015), 9-18.

22 Alejos Grau, 29-36; Neirotti y Mattalini, 209-212. 
Vaticano II, pero inconformes con un esquema conciliar europeo que impedía discutir plenamente muchas de las problemáticas latinoamericanas. ${ }^{23}$

Aunque este proceso ha sido muy poco estudiado para el caso de la Guerra Fría centroamericana, la política del istmo también se vio profundamente impactada por las reformas conciliares; el catolicismo tuvo una importancia trascendental en la renovación de las culturas políticas regionales, en el surgimiento de nuevas organizaciones y movimientos revolucionarios, de resistencia política e ideológica. Al analizar el papel de la intelectualidad juvenil católica en la fundación de la nueva izquierda en El Salvador durante las décadas de 1950 y 1970, Joaquín Chávez explica cómo, de manera inesperada para las jerarquías eclesiásticas, las ideas del Concilio Vaticano II fueron la génesis de un proceso de radicalización juvenil y el surgimiento de un «anticapitalismo católico», que se identificaba ética y religiosamente con las personas en condiciones de pobreza y marginalización social. El historiador explica cómo, desde un punto de vista institucional, las reformas eclesiásticas tenían la intención de preservar la influencia tradicional del catolicismo en América Latina; pero esto se materializó en todo lo contrario, al abrir las puertas para que confluyeran jóvenes intelectuales, tanto católicos, como marxistas de la Universidad de El Salvador y de partidos políticos, en un diálogo que facilitó el surgimiento de la nueva izquierda y la guerrilla en momentos que, inclusive, antecedían a los reconocidos teólogos de la liberación en ese país. ${ }^{24}$

Por su parte, historiadores e historiadoras de la Guerra Fría alrededor del mundo han propuesto que durante la década de 1960 confluyeron importantes procesos de cambio global. ${ }^{25}$ Así, los estudios sobre los Global Sixties buscan superar el análisis bipolar y diplomático de las visiones más tradicionales sobre la Guerra Fría y, al hacerlo, explicitan con claridad la transnacionalidad de coyunturas históricas ocurridas en esa década, y se preocupan por el impacto político, económico y cultural causado en los países del Tercer Mundo. Además, buscan comprender los cambios locales del decenio dentro de un marco transnacional y proponen que el surgimiento de la nueva izquierda, movimientos contraculturales, lenguajes comunes de disidencia política y nuevas organizaciones y culturas juveniles, ocurrieron en geografias disímiles, pero en un contexto de simultaneidad histórica. Esto sugiere causas comunes y, para el caso de América

23 Bonnin, Discurso político..., 38-41.

24 Joaquín Chávez, "Catholic Action, the Second Vatican Council, and the Emergence of the New Left in El Salvador (1950-1975)», The Americas, 70, n. 3 (2014): 459-487, https://doi.org/10.1017/ S0003161500003990.

25 El libro que inauguró este campo de estudios es: Karen Dubinsky, Catherine Krull, Susan Lord, Sean Mills, y Scott Rutherford (ed.), New World Coming: The Sixties and the Shaping of Global Consciousness (Toronto: Between the Lines, 2009); puede verse, también, el trabajo colectivo de síntesis más reciente sobre la década: Jian Chen, Martin Klimke, Masha Kirasirova, Mary Nolan, MarilynYoung y JoannaWaley-Cohen (ed.), The Routledge Handbook of the Global Sixties: between protest and nation-building (Nueva York: Routledge, 2018). 
Latina, una visión del pasado más compleja, que debe tomar en cuenta «imágenes, actores, ideas y paisajes sonoros que constituyeron la década global de los años sesenta». ${ }^{26}$

En materia religiosa, los actores, imágenes e ideas que constituyeron esa década son algunos de los ejes que el historiador Eric Zolov ha puntualizado para comprender el carácter global del decenio y el nacimiento de «espiritualidades alternativas» que surgieron por discusiones transnacionales como el Concilio Vaticano II en muchos otros países latinoamericanos, las cuales causaron una intensa discusión global de las jerarquías y bases eclesiásticas, al establecer un cuestionamiento a la institucionalidad religiosa, a sus doctrinas y prácticas tradicionales. ${ }^{27}$ Consecuentemente, la propuesta de comprender la década de 1960 en perspectiva global es de gran valor para este estudio, pues tal y como lo señala el mismo Chávez, la experiencia salvadoreña muestra cómo un grupo de intelectuales jóvenes adscrito al catolicismo y enterado de las discusiones transnacionales del Concilio Vaticano II, dio forma a una generación de ruptura y cristalizó un interesante eclecticismo en innovadoras teorías y estrategias revolucionarias que permitieron una de las insurgencias populares más importantes e impactantes de América Latina durante todo el siglo XX. ${ }^{28}$

Propuestas como las anteriores invitan a analizar el contexto global de la Guerra Fría desde una perspectiva «descentrada» que insiste en que, durante ese contexto global, no solamente los Estados Unidos y la Unión Soviética jugaron papeles de primer orden; de igual manera evita el argumento tradicional que insiste en las influencias «centro-periferia». Un énfasis descentrado rechazaría los condicionamientos que ambas potencias ejercieron sobre los llamados países del Tercer Mundo y le daría una mayor importancia a la agencia de los actores regionales..$^{29}$ Así, el caso salvadoreño ejemplifica que la agencia de algunos actores juveniles permitió experiencias de radicalización a partir de ideas religiosas.

Pero tomando en cuenta el contexto global y regional, así como la perspectiva de análisis señalada, es claro que las expectativas que tenían los líderes católicos sobre las personas jóvenes, sobre sus ideas y sus acciones estaban inspiradas en un efecto de desradicalización política. Cuando el papa Pablo VI pronunció el mensaje final del Concilio Vaticano II en 1965, presentó la reunión de cuatro años como un esfuerzo del catolicismo por «rejuvenecer su rostro» y por proyectar la institución en el porvenir que heredaría la juventud, a quien dedicó

26 Eric Zolov, «Latin America in the Global Sixties», The Americas, 70, n. 3 (2014): 394-362, https://doi. org/10.1017/S0003161500003953.

27 Ibíd., 358.

28 Chávez, «Catholic Action...», 484-487; véase, Joaquín Chávez, "The University for Social Change and the Legacy of Ignacio Martín-Baró, S. J.», Peace and Conflict: Journal of Peace Psychology, 18, n. ${ }^{\circ} 1$ (2012): 68-76, https://doi.org/10.1037/a0026866.

29 Jadwiga E. Pieper Mooney y Fabio Lanza (ed.), De-centering Cold War History: local and global change (Londres: Routledge, 2012). 
el Concilio y las últimas palabras de su discurso, con lo cual colocó, en el centro de las discusiones religiosas, a un actor político emergente que tendría un papel protagónico durante esa década y el resto del siglo. ${ }^{30}$

Ese mensaje papal estaba dirigido a las personas «jóvenes de uno y otro sexo del mundo entero», a quienes, a pesar de sus múltiples identidades juveniles, el pontífice parecía comprender como una población homogenizada y global. El concepto de juventud propuesto por el líder de la Iglesia al finalizar la reunión transnacional de obispos se caracterizaba por la desradicalización política y por el «encanto» de «darse sin recompensa». El concepto era totalizante, al representar a la «verdadera juventud del mundo» como sujetos «generosos, puros, respetuosos, sinceros» y como imitadores de «Cristo, eternamente joven, el héroe verdadero, humilde y sabio, el profeta de la verdad y del amor, el compañero y amigo de los jóvenes». Además, permeado por el discurso dominante de la Guerra Fría, alentaba a esa juventud a resistir a las «tentaciones» y «filosofías» que habían «seducido» a sus mayores; a rechazar «los instintos de violencia y de odio, que engendran las guerras», y sustituirlas por «la certeza de la existencia de un Dios justo y bueno». ${ }^{31}$

Esa interpretación monolítica de Cristo, de la juventud y la representación sobre las filosofías que habían "seducido» a las personas adultas y habían generado escenarios globales de violencia insinuaba una idea muy extendida durante la Guerra Fría y que tuvo un importante eco dentro de la producción de conocimiento sobre esa coyuntura. Tal interpretación insistía en la equiparación de los Estados Unidos y la Unión Soviética como potencias militares en busca de un objetivo común: la hegemonía ideológica en todo el mundo. Al estudiar la producción académica sobre la Guerra Fría, algunos historiadores han identificado una tendencia historiográfica post-revisionista que surgió hacia la década de 1980 y que afirmaba que el origen del conflicto se debía a una «responsabilidad mutua» de los Estados Unidos y la Unión Soviética; este argumento, novedoso en su contexto y similar al de Pablo VI, rompía con las tradiciones ortodoxas de los decenios de 1950 y 1960, que afirmaban que esa responsabilidad era solamente de alguna de las dos potencias. ${ }^{32}$

En el caso de Juan Pablo II, es claro que su vocabulario sobre la juventud, las ideologías y la política estaban mediados por su experiencia personal. Como polaco que nació en 1920, la juventud de Karol Wojytla estuvo marcada por la ocupación nazi de su país durante la Segunda Guerra Mundial (1939-1945); en 1946, cuando empezó a ser sacerdote, ya Polonia tenía un año de ser gobernada

30 Pablo VI, «Mensaje del Concilio Vaticano II a los jóvenes», Vatican, 7 de diciembre de 1965.

31 Ibíd.

32 Michael Hopkins, «Continuing Debate and New Approaches in Cold War History», The Historical Journal, 50, n. ${ }^{\circ} 4$ (2007): 913-934, https://doi.org/10.1017/S0018246X07006437; Bogdan Antoniu, «The Origins of the Cold War a Historiographical Review», Euro-Atlantic Studies, n. ${ }^{\circ} 3$ (2000): 33-46, https://www. ceeol.com/search/article-detail?id=648402. 
por el comunismo soviético y ese contexto político que se extendería hasta el ocaso de la Guerra Fría, había motivado en él un discurso profundamente anticomunista. ${ }^{33}$ De esa manera, aunque sostendría un discurso similar sobre la juventud, Juan Pablo II se despegaría de un argumento como el de la «responsabilidad mutua» para explicar la Guerra Fría y eso fue evidente en el vocabulario político que utilizó en Centroamérica y lo era desde el inicio de su papado en 1978.

Personas especializadas en la retórica de Juan Pablo II afirman que él pregonó sus discursos políticos de manera particularmente cuidadosa. ${ }^{34}$ Indudablemente, cada discurso era cauteloso o sacaba provecho del contexto en que era leído; sin embargo, los dirigidos a las juventudes evidencian que estos fueron momentos aprovechados por él para establecer relaciones entre las personas jóvenes de su actualidad, el comunismo, la incertidumbre y la juventud, como heredera y forjadora del porvenir. En la visita que realizó a la República Federal de Alemania en noviembre de 1980, el papa ofreció una misa en Múnich para la juventud, donde se identificó con la «inseguridad» que las juventudes podían sentir frente al futuro y evidenció una perspectiva bipolar de la Guerra Fría, al cuestionarse: «¿Cómo le irá a este mundo nuestro, dividido en bloques militares de poder $[\ldots]$ en Estados libres y totalitarios?», e inmediatamente, añadió:

Continuamente surgen guerras, en esta $u$ otras latitudes de la tierra, que causan muerte y miseria entre los hombres. Y por otro lado, en muchas partes del mundo, cerca o lejos, se registran actos de la más cruda violencia y de sangriento terrorismo [...] Por eso, no pocos jóvenes de entre vosotros destruyen su ser interno de hombres refugiándose en el alcohol y las drogas. A menudo, tras esa actitud se encuentra la angustia y la desesperación; pero otras veces ese comportamiento oculta la búsqueda del placer, la falta de autocontrol o una irresponsable curiosidad de 'probarlo' todo [...] También hay quienes huyen de esa verdad básica hacia el exterior, militando en utopías políticas y sociales o en cualquier quimera de la vida social. Por muy necesarios que sean los ideales y las metas propuestas, las 'fórmulas mágicas' utópicas ya no pueden ayudarnos, sobre todo cuando, como ocurre la mayoría de las veces, van acompañados de un poder totalitario o del uso de una fuerza destructora. ${ }^{35}$

En su cuestionamiento inicial y su vocabulario político, es claro que el papa pensaba en un mundo bipolar: caracterizó a cada uno de esos polos con conceptos tan antagónicos como la libertad y el totalitarismo y pensaba en los territorios fuera del bloque capitalista alemán para ubicar allí la falta de libertad, la violencia, el terrorismo y el derramamiento de sangre por causa de las guerras. Pero el papa fue más allá; al relacionar el concepto de la juventud con

33 Gillis, 11.

34 Joseph Blaney y Joseph Zompetti (ed.), The Rhetoric of Pope John Paul II (Nueva York: Lexington Books, 2009).

35 Juan Pablo II, «Viaje apostólico a la República Federal de Alemania. Misa para los jóvenes. Homilía del Santo Padre Juan Pablo II», Vatican, 19 de noviembre de 1980. 
temáticas de larga trayectoria para 1980 como el consumo de drogas y la militancia política, repitió un concepto de juventud totalmente influenciado por el discurso dominante de la Guerra Fría, que imaginaba una conspiración soviética para dominar las mentes juveniles del mundo entero y que indudablemente, le daba una nula importancia a la agencia política de esas personas a causa de su «idealismo», «entusiasmo», «irresponsabilidad», «curiosidad» y pensamiento mágico. Además, el papa incluyó el concepto del terrorismo, que vaciaba de contenido político las acciones de la juventud y las ubicaba en el plano del terror, la violencia desmedida y la destrucción de la sociedad. ${ }^{36}$

Es evidente que él mismo se preocupó de manera constante por elaborar un concepto transnacional sobre la juventud, que le permitiera a la Iglesia católica enmarcar a este sector de la sociedad en el escenario de la Guerra Fría y también es claro que, como los conceptos tradicionales sobre la juventud, buscó una definición «global» de ella. Las biografías sobre el papa y sus memorias afirman que él mismo tenía una larga relación con ese concepto: como sacerdote fue cercano a las juventudes católicas y universitarias de Polonia; él mismo, con 47 años había sido presentado como el cardenal más «joven» de su época y, una década más tarde, se convirtió en el papa con menor edad del siglo XX. ${ }^{37}$

Esta razón también contribuyó a que, desde el inicio de su papado y a lo largo de toda la década de 1980, el papa se reuniera en múltiples ocasiones con distintas agrupaciones católicas de jóvenes. Algunas de las primeras veces que lo hizo fue en 1979, cuando recibió a miles de jóvenes en el Vaticano, cuando visitó México y cuando regresó a Polonia. ${ }^{38}$ En esos y muchos otros momentos, él insistió en definir el concepto de juventud como una «fase de formación», es decir, caracterizado por la condición estudiantil y la adscripción de este sector de la sociedad a las instituciones de educación formal y las universidades. Estando en Cracovia, se extendió en sus ideas sobre la universidad, ${ }^{39}$ recordó sus años como estudiante y profesor e insistió en que la formación de la juventud debía realizarse en «los años académicos, en el tiempo de los estudios superiores» y al pensar en las juventudes con las que había tenido encuentros, evidenció el carác-

36 Ibíd.

37 George Weigel, Witness to Hope: The Biography of Pope John Paul II (Nueva York: Harper Perennial, 2005); Juan Pablo II, Historia de mi vida (Madrid: Editorial Encuentro, 2015).

38 Juan Pablo II, «Discurso del Santo Padre Juan Pablo II a más de seis mil estudiantes universitarios procedentes de todo el mundo», Vatican, 10 de abril de 1979; Juan Pablo II, «Carta del Santo Padre Juan Pablo II a los participantes en el encuentro celebrado en el Santuario de Guadalupe», Vatican, 15 de febrero de 1979; Juan Pablo II, «Peregrinación apostólica a Polonia. Santa misa para la juventud universitaria: homilía de su Santidad Juan Pablo II», Vatican, 3 de junio de 1979; véase, también: Cezar M. Ornatowski, «Rhetoric of Pope John Paul II's Visits to Poland, 1979-1999», en: The rhetoric of Pope John Paul II, (ed.) Joseph Blaney y Joseph Zompetti (Nueva York: Lexington Books, 2009), 103-150.

39 Peter M. Collins, A Twentieth-Century Collision: American Intellectual Culture and Pope John Paul II's Idea of a University (Maryland: University Press of America, 2010); Carlos Julio Cuartas, «La idea de universidad en Juan Pablo II», Theologica Xaveriana, n. ${ }^{\circ} 146$ (2003): 163-189, https://revistas.javeriana. edu.co/index.php/teoxaveriana/article/view/20884. 
ter monolítico de su concepto de juventud al afirmar: «¡Cuánto se asemejan entre sí los estudiantes de todas partes!». ${ }^{40}$

Estudios sobre el concepto de juventud dejan claro que esta es una de las maneras más tradicionales de comprender a este sector de la población, pero también afirman que entre las décadas de 1960-1980 el mundo occidental homologó conceptos como los de juventud y estudiantado casi como sinónimos, al ser los centros educativos los lugares donde más evidente era la presencia juvenil. ${ }^{41}$ Para el caso del discurso papal, una ampliación de ese concepto solo fue evidente en una visita a Costa de Marfil en mayo de 1980. Allí, Juan Pablo II nuevamente ofreció una misa para la juventud estudiantil, valorada por él como la portadora del liderazgo político del futuro y como la responsable de «otras» juventudes, aquellas que «realizan su trabajo y contribuyen como obreros y agricultores, a la producción y al éxito económico», es decir, en quienes no tenían trabajo ni acceso a la educación. ${ }^{42}$

Además, muchos de los discursos de Juan Pablo II eran leídos frente a personas jóvenes que «peregrinaban» hasta el Vaticano y que pertenecían a las organizaciones juveniles que proliferaron en la Iglesia católica después del Concilio. Por esto, es interesante que la ampliación discursiva de su concepto de juventud solamente fue posible en una visita a un país del Tercer Mundo, porque el estudio de sus discursos en lugares como el Vaticano y otros países de Europa evidencian una menor preocupación discursiva por temáticas como el desempleo, la militancia política o el consumo de drogas. Al contrario, estos discursos resaltaban «virtudes juveniles», profundamente adultocéntricas y estereotipadas como el amor, la inocencia, la «frescura», la adhesión a la nobleza, la amistad, la caridad y la solidaridad. Otros abordaban temáticas relacionadas directamente con personajes bíblicos o eclesiásticos y algunas otras insistían en ideas morales sobre la sexualidad y la familia. ${ }^{43}$

La primera vez que Juan Pablo II definió públicamente el concepto de juventud lo hizo en 1979, en una visita a los Estados Unidos, donde reconoció a la juventud como personas con «el derecho a ser dinámicos, creativos y espontáneos; el derecho a vivir en plenitud la esperanza y la alegría; la oportunidad de

40 Juan Pablo II, «Peregrinación apostólica a Polonia. Discurso del papa Juan Pablo II a los jóvenes universitarios», Vatican, 8 de junio de 1979.

41 Sandra Souto Kustrín, «Juventud, teoría e historia: la formación de un sujeto social y de un objeto de análisis», Historia Actual Online (España), n. 13 (2007): 171-192; Enzo Faletto Verné, «La juventud como movimiento social en América Latina», Revista de la CEPAL, n. ${ }^{\circ} 29$ (1986): 185-191.

42 Juan Pablo II, «Viaje apostólico a África. Misa para los estudiantes de Costa de Marfil. Homilía del Santo Padre Juan Pablo II», Vatican, 11 de mayo de 1980.

43 La cita es de: Juan Pablo II, «Alocución del papa Juan Pablo II. A los jóvenes en la Basílica de San Pedro», Vatican, 10 de enero de 1979; pero las temáticas son una síntesis de: Juan Pablo II, «Encuentro del Santo Padre Juan Pablo II con los jóvenes en la Basílica Vaticana», Vatican, 8 de febrero de 1979; Juan Pablo II, «Discurso del Santo Padre Juan Pablo II a los jóvenes del movimiento 'Comunión y Liberación'», Vatican, 31 de marzo de 1979; Juan Pablo II, «Discurso del Santo Padre Juan Pablo II a los muchachos de la Acción Católica Italiana», Vatican, 26 de mayo de 1979. 
explorar el maravilloso mundo de la ciencia y el conocimiento; y, sobre todo, la suerte de entregaros personalmente a los demás en un servicio alegre y generoso»». ${ }^{44}$ Un año más tarde, pero en Francia, al concepto que ensayaba también le añadió aspectos como la «inestabilidad» propia de la edad juvenil, la «desconfianza» frente a las «verdades», la «inquietud por el futuro y las dificultades de inserción profesional», la «impotencia» $\mathrm{y}$ «las tentaciones de revuelta». También, volvió a la idea global del concepto al afirmar que, a pesar de las diversidades geográficas, «los jóvenes» eran «muy parecidos en sus entusiasmos y en sus decepciones, en sus aspiraciones y en su generosidad». ${ }^{45}$

En sus próximos discursos, este concepto fue repetido frente a las organizaciones juveniles que siguieron visitándolo en el Vaticano y que asistieron a concentraciones para escucharle en otros lugares del mundo. Adicionalmente a la construcción de esa idea, el papa insistía en que la juventud era depositaria del futuro, la responsable de construir la paz mundial, ${ }^{46}$ la llamada a buscar la «verdad» y la «verdadera» imagen juvenil en la figura de Cristo. ${ }^{47}$ En este sentido, la elaboración más acabada del concepto de juventud del máximo líder de la Iglesia católica fue expuesto en una larga «Carta Apostólica» para «los jóvenes y las jóvenes del mundo», publicada en 1985 con ocasión de la declaratoria de la Organización de las Naciones Unidas (ONU) del Año Internacional de la Juventud. Allí, él trató de sintetizar sus ideas y anotó:

[Hay] razones - incluso de tipo objetivo - para pensar en la juventud como en una singular riqueza que el hombre experimenta precisamente en tal período de su vida. Este se distingue ciertamente del período de la infancia - es, en efecto, la salida de los años de la infancia—, como se distingue también del período de la plena madurez. Efectivamente, el período de la juventud es el tiempo de un descubrimiento particularmente intenso del 'yo' humano y de las propiedades y capacidades que éste encierra. A la vista interior de la personalidad en desarrollo de un joven o de una joven se abre gradual y sucesivamente aquella específica - en cierto sentido única e irrepetible - potencialidad de una humanidad concreta, en la que está como inscrito el proyecto completo de la vida futura. La vida se delinea como la realización de tal proyecto, como 'autorrealización' [...] si queremos expresarlo

44 Juan Pablo II, «Viaje apostólico a los Estados Unidos de América. Discurso del Santo Padre Juan Pablo II a los estudiantes de la Universidad Católica», Vatican, 7 de octubre de 1979.

45 Juan Pablo II, «Viaje apostólico a París y Lisieux. Discurso del Santo Padre Juan Pablo II a los jóvenes reunidos en el Parque de los Príncipes», Vatican, 1 de junio de 1980.

46 Juan Pablo II, «Mensaje de su Santidad Juan Pablo II para la celebración de la XVIII Jornada Mundial de la Paz», Vatican, 1 de enero de 1985.

47 Juan Pablo II, «Viaje apostólico a los Estados Unidos de América. Discurso del Santo Padre Juan Pablo II a los estudiantes en el Madison Square Garden», Vatican, 3 de octubre de 1979; Juan Pablo II, «Visita pastoral a Umbría. Encuentro del Santo Padre Juan Pablo II con los jóvenes», Vatican, 23 de marzo de 1980; Juan Pablo II, «Discurso del Santo Padre Juan Pablo II a una peregrinación de universitarios franceses», Vatican, 5 de abril de 1980; Juan Pablo II, «Discurso del Santo Padre Juan Pablo II a los Consejos Directivo y General del Centro de Iniciativa Juvenil», Vatican, 29 de abril de 1980; Juan Pablo II, «Santa misa para el Movimiento GEN — Generación Nueva—. Homilía del Santo Padre Juan Pablo II», Vatican, 18 de mayo de 1980. 
brevemente, se revela precisamente el perfil y la forma de riqueza que es la juventud. Es la riqueza de descubrir y a la vez de programar, de elegir, de prever y de asumir como algo propio, las primeras decisiones, que tendrán importancia para el futuro en la dimensión estrictamente personal de la existencia humana. Al mismo tiempo, tales decisiones tienen no poca importancia social. ${ }^{48}$

Inicialmente, su idea eliminó el contenido político y argumentos polémicos como los que ya había expuesto antes; ese concepto se centró en la individualidad, silenció el contexto político de la Guerra Fría y homogenizó las experiencias juveniles; pero, al avanzar en su contenido, también consideró la educación, visiones morales sobre la sexualidad, el «desafío juvenil» de vehiculizar la paz del futuro y de luchar contra las ideologías y prácticas alejadas de la doctrina de la Iglesia. ${ }^{49} \mathrm{Si}$ se toman en consideración los estudios sobre la Guerra Fría, la idea sobre juventud que elaboró el papa no solamente era la de un personaje diplomático y anticomunista, se trataba de un concepto monolítico pero elaborado en el bloque capitalista de Europa, que principalmente consideraba la experiencia de las juventudes de ese continente y que no se detenía a «descentrar» tal definición. Es decir, aunque la juventud imaginada por Juan Pablo II tenía la pretensión de ser «global», no pensaba de forma expresa en las especificidades de «otras» juventudes, que experimentaban procesos locales de gran complejidad y es claro que este no era un error exclusivo del papa. Ya desde 1979, Pierre Bourdieu insistía en que solo un aventurado uso del lenguaje podía pretender agrupar en un concepto a un sector de la sociedad cuya única característica compartida es la edad. ${ }^{50}$

Así, es importante anotar que este aventurado uso del lenguaje era practicado por políticas públicas y líderes de todo el mundo, pero también es cierto que para el momento en que el papa hablaba y ensayaba sus conceptos, la jerarquía eclesiástica de otros lugares del planeta se preocupaba por adaptar la doctrina religiosa y los conceptos propuestos por el Concilio Vaticano II a sus realidades locales. Uno de esos casos era la Iglesia católica en América Latina, que Juan Pablo II afirmaba conocer desde 1980, cuando en una visita que realizó a Brasil y, sorprendido por ver una cantidad tan sobresaliente de jóvenes, comprendió «por qué los obispos de Puebla hablan de opción preferencial por los jóvenes». Según él, tal opción implicaba «anunciar incesantemente a los jóvenes un mensaje de liberación plena», ${ }^{51}$ pero, ¿qué significaba adoptar una «opción preferencial por

48 Juan Pablo II, «Carta apostólica Dilecti Amici del papa Juan Pablo II a los jóvenes y a las jóvenes del mundo con ocasión del Año Internacional de la Juventud», Vatican, 31 de marzo de 1985.

49 Ibíd.

50 Pierre Bourdieu, «La 'juventud’ no es más que una palabra», en: Sociología y cultura, (ed.) Pierre Bourdieu (Ciudad de México: Grijalbo, 2002), 163-173.

51 Juan Pablo II, «Viaje apostólico a Brasil. Homilía del Santo Padre Juan Pablo II durante la misa para los jóvenes», Vatican, 1 de julio de 1980. 
los jóvenes» durante la Guerra Fría?, ¿qué visiones sobre la juventud se construyeron y cómo se materializaron esas ideas?

\title{
Un nuevo cuerpo: la juventud católica de América Latina
}

Juan Pablo II llegó a Brasil en julio de 1980, con solo dos años de ser papa y a tan solo un año y medio de distancia de la reunión que los obispos latinoamericanos del CELAM habían realizado en el Estado mexicano de Puebla. Allí, tal y como lo haría en el bloque capitalista de Alemania, su discurso para las juventudes se detuvo en argumentos hondamente anticomunistas. Frente a ellas, recordó las actividades políticas de sus años como estudiante y sacerdote joven y al evaluarlas, apeló a un discurso liberal para asegurar que «la justicia social sólo es verdadera si está basada en los derechos del individuo». Según él, el camino para alcanzar tales derechos estaba en reconocer «al hombre» como semejante a Dios y negar tal semejanza implicaba «reducir el hombre a instrumento de dominio [...] o a la omnipotencia del Estado totalitario». La práctica discursiva del papa en suelo latinoamericano tiene una importancia sobresaliente; en él se infiere un intento por comprender la realidad política de la región que visitaba y eso le hizo verbalizar ideas inéditas. En una de ellas, el líder formuló un condicionamiento político para responder cómo una persona joven podría empezar a «envejecer» y cómo se dejaba de ser un «buen cristiano»:

\begin{abstract}
Aprendí que un hombre cristiano deja de ser joven y no será buen cristiano, cuando se deja seducir por doctrinas e ideologías que predican el odio y la violencia [...] aprendí que un joven comienza peligrosamente a envejecer cuando se deja engañar por el principio, fácil y cómodo, de que «el fin justifica los medios»; cuando llega a creer que la única esperanza para mejorar la sociedad está en promover la lucha y el odio entre los grupos sociales, en la utopía de una sociedad sin clases, que se revela muy pronto como creadora de nuevas clases [...] Si el joven que yo fui, llamado a vivir la juventud en un momento crucial de la historia, puede decir algo a los jóvenes que sois vosotros, creo que os diría: ¡No os dejéis instrumentalizar! [...] Procurad ser bien conscientes de lo que pretendéis y de lo que hacéis. $\mathrm{Y}$ veo que eso mismo os dijeron los obispos de América Latina, reunidos en Puebla el año pasado: 'Debe formarse en el joven el sentido crítico frente a los contravalores culturales que las diversas ideologías tratan de transmitirle' (Documento de Puebla, núm. 1197), especialmente las ideologías de carácter materialista, para que no sea manipulado por ellas. Y el Concilio Vaticano II dice: «El orden social hay que desarrollarlo a diario, fundarlo en la verdad, edificarlo sobre la justicia, vivificarlo por el amor. Pero debe encontrar en la libertad un equilibrio cada día más humano». ${ }^{52}$
\end{abstract}

El contenido anticomunista del discurso es sobresaliente por su adscripción a valores tan elementales del capitalismo como los derechos individuales, por su ataque directo contra el marxismo y la eliminación de las clases sociales, al homologarlos con el surgimiento de nuevas clases y el odio entre grupos 
sociales. Pero si la tercera Conferencia General del CELAM en Puebla era un intento de la Iglesia católica de América Latina por actualizar e interpretar los acuerdos del Concilio Vaticano II y leerlo frente a la realidad política, social y cultural de la región, ahora Juan Pablo II, como autoridad hegemónica de la Iglesia, se empeñó en desestimar este esfuerzo, en interpretar él mismo el contenido de esa reunión latinoamericana y en agregar a su interpretación el discurso bipolar sobre la Guerra Fría, sin tomar en cuenta la agencia de los actores eclesiásticos regionales. Para hacerlo, tomó un fragmento del documento escrito en Puebla que hablaba del rescate de los valores culturales de la región frente a las «diversas ideologías» — en plural — y lo puso junto a otro del Concilio, sobre el orden social y la libertad. ¿Qué motivó al papa a formular su afrenta específicamente en Brasil y qué lo hizo viajar hasta allí para interpretar un proceso latinoamericano?

Una década antes de la tercera Conferencia General del CELAM en Puebla, los obispos latinoamericanos se habían reunido durante agosto y setiembre de 1968 en el municipio colombiano de Medellín. Quienes desde distintas disciplinas han analizado ese evento y sus repercusiones, están de acuerdo en afirmar que este fue un momento clave en el que los obispos de la región se reunieron por primera vez para leer el Concilio Vaticano II - el título de la Conferencia fue «La Iglesia en la actual transformación de América Latina a la luz del Concilio»_. ${ }^{53}$ Entre otros aspectos, allí sobresalía una inclinación «progresista» de la jerarquía eclesiástica, que incluyó una discusión sobre la pobreza y ese fue el impulso que daría fuerza a movimientos como la «Iglesia de los pobres», la Teología de la Liberación y las Comunidades Eclesiales de Base, ${ }^{54}$ que causaron un impacto trascendental en la radicalización política de toda la región latinoamericana y profundos impactos en los conflictos armados de las décadas de 1970 y 1980 en Centroamérica.

Al exponer el surgimiento de los liderazgos guerrilleros centroamericanos, Dirk Kruijt señala algunos focos de agitación política como los movimientos estudiantiles, los partidos políticos y los ecos de la Revolución cubana; pero le da una importancia central a la Teología de la Liberación y a las Comunidades Eclesiales de Base. Casos emblemáticos como los de El Salvador y Nicaragua así lo demuestran; de allí no solamente surgieron figuras importantes como los sacerdotes Ignacio Ellacuría y Ernesto Cardenal, sino que tales movimientos, reunidos para estudiar La Biblia y discutir sobre sus realidades nacionales y cotidianas, crecieron exponencialmente durante la década de 1970

53 Cfr. Consejo Episcopal Latinoamericano, La Iglesia en la actual transformación de América Latina a la luz del Concilio. II Conferencia General del Episcopado Latinoamericano (Bogotá: Secretariado General del Consejo Episcopal Latinoamericano, 1970); Alberto Ramírez, «La Conferencia de Medellín y la Teología de la Esperanza», Cuestiones Teológicas, 35, n. ${ }^{\circ} 84$ (2008): 235-254, https://revistas.upb.edu.co/index. $\mathrm{php} /$ cuestiones/article/view/44.

54 Acevedo Tarazona y Delgado Díaz, 245-268; Bonnin, Discurso político..., 39-41. 
y se radicalizaron en coyunturas críticas como la Revolución sandinista y el conflicto armado salvadoreño. ${ }^{55}$

Por su parte, el Consejo Episcopal Latinoamericano tenía su propia trayectoria y esa misma institución tuvo cambios profundos después de la reunión de 1968 en Medellín: impuesta desde 1899 por el papa León XIII, no fue sino hasta 1955 cuando Pío XII convocó a la primera Conferencia General de la CELAM, que se realizó en Río de Janeiro y que significó su fundación oficial. En su estudio sobre los documentos finales de Medellín, Bonnin afirma que inicialmente la creación del CELAM tuvo la resistencia de muchos obispos que veían en la nueva institución una reducción de sus poderes locales. Así, esto motivó a que fueran los obispos y sacerdotes más «jóvenes» quienes canalizaran el desinterés de sus mayores para apropiarse de la institución, darle un perfil innovador, dinámico y una importancia inédita a las ciencias sociales en el diagnóstico y la planificación, tomando en cuenta los aportes teóricos y las realidades sociales de la región. ${ }^{56} \mathrm{El}$ mismo Bonnin explica que en el proceso de redacción de los documentos floreció una compleja red de negociaciones, conflictos y oposición a la Teología de la Liberación, que se alimentaba del diálogo de católicos y marxistas para fundar una perspectiva latinoamericana que adoptaba «como lugar teológico el mundo de los pobres $»^{57}$ e interpretaba los textos bíblicos «como la demanda de Cristo de liberar a las masas de la pobreza y la represión».. ${ }^{8}$

Aquella oposición no era para menos; en medio de la Guerra Fría, un sector progresista de la Iglesia católica de América Latina adoptó en Medellín una «opción preferencial por los pobres», poniendo en jaque el discurso de los Estados Unidos que insistía en luchar contra un comunismo ateo que se expandía por toda la región. Ese sector progresista adoptó su posición en favor de los grupos pobres desde una lectura marxista de la teología, que les permitía establecer paralelismos entre Cristo y el Che Guevara, que llamaba a los sacerdotes a «defender los derechos de los oprimidos, promover organizaciones de base y priorizar a los pobres» ${ }^{59}$ Frente a eso, no es extraño que un hombre anticomunista e influyente como Juan Pablo II llevara la versión más radical de su discurso hasta la región y que lo manifestara frente a las juventudes, un sector que, si bien había sido considerado en el Concilio de 1965, seguramente recibió más

55 Dirk Kruijt, Guerrilla: guerra y paz en Centroamérica (Ciudad de Guatemala: F\&G Editores, 2009), 93-101; véase los capítulos 4 y 5 sobre las Comunidades Eclesiales de Base en Morazán (El Salvador) y sobre el pensamiento de Ignacio Ellacuría y su influencia en el conflicto armado en El Salvador de: Jeffrey Gould, Desencuentros y desafios: ensayos sobre la historia contemporánea (San José: Centro de Investigaciones Históricas de América Central, 2016), 99-141.

56 Bonnin, Discurso politico..., 32-36.

57 Bonnin, «Las voces...», 17-18.

58 Kruijt, 95.

59 Ibíd. 
atención en Medellín, debido a la simultaneidad de protestas estudiantiles que se desarrollaban en muchas regiones del mundo durante 1968. ${ }^{60}$

Ese interés quedó tímidamente demostrado por Pablo VI desde su discurso de apertura de la segunda Conferencia General del CELAM en Medellín. Era la primera vez que un papa visitaba América Latina y, allí, de forma muy breve, se dirigió a «jóvenes y estudiantes» para admitir que aquel se trataba de un tema «digno del máximo interés y de grandísima actualidad». ${ }^{61}$ Mucha más importancia le dieron los documentos finales de Medellín a las temáticas juveniles: en un apartado dedicado por completo al tema, el documento inventó un concepto de juventud y estableció recomendaciones puntuales sobre cómo llevarlo a la acción. Así, el documento de Medellín definió a la juventud como el sector más numeroso en América Latina y como una fuerza de presión social:

Se presenta en gran parte del continente, como un nuevo cuerpo [...] portador de sus propias ideas y valores y de su propio dinamismo interno. Busca participar activamente, asumiendo nuevas responsabilidades y funciones, dentro de la comunidad latinoamericana. Con frecuencia, la imposibilidad de participación en la vida de la sociedad, provoca en ella una cierta obligada marginalidad. Vive en una época de crisis y de cambios que son causa de conflictos entre diversas generaciones [pero] mientras un sector de la juventud acepta pasivamente las formas burguesas de la sociedad -dejándose llevar a veces por un indiferentismo religioso-, otro rechaza con marcado radicalismo el mundo que han plasmado sus mayores por considerar su estilo de vida falto de autenticidad; rechaza igualmente una sociedad de consumo que masifica y deshumaniza [...] La juventud, particularmente sensible a los problemas sociales reclama los cambios profundos $\mathrm{y}$ rápidos que garanticen una sociedad más justa; reclamos que a menudo se siente tentada a expresar por medio de la violencia. Es un hecho comprobable que el excesivo idealismo de los jóvenes los expone fácilmente a la acción de grupos de diversas tendencias extremistas [...] Su actitud religiosa se caracteriza por el rechazo de una imagen desfigurada de Dios que a veces les ha sido presentada y por la búsqueda de auténticos valores evangélicos [...] la juventud aporta indudablemente un conjunto de valores, acompañados no obstante de aspectos negativos [...] en primer término, una tendencia a la personalización, conciencia de sí mismos, creatividad, que por contraste los lleva a rechazar los valores de la tradición. Poseen un idealismo excesivo que los lleva a desconocer realidades innegables que han de ser aceptadas, y a adoptar un inconformismo radical cuyas manifestaciones características se dan casi en todos los países y que impulsa a pretender construir todo de nuevo con prescindencia absoluta del pasado. Característica de la juventud es también la espontaneidad que la lleva a un menosprecio no siempre justificado de las formas institucionales, de las normas, de la autoridad y del formalismo. Presenta, finalmente, un conjunto de valores en el plano de la relación comunitaria, ciertas formas de responsabilidad, una voluntad de autenticidad y de sinceridad, una aceptación de los demás, tales como lo son un franco reconocimiento del carácter pluralista de la sociedad. Esta

60 Jeffrey Gould, «Solidarity Under Siege: The Latin American Left, 1968», The American Historical Review, 114, n. ${ }^{\circ} 2$ (2009): 348-375, www.jstor.org/stable/30223783.

61 Pablo VI, «Peregrinación apostólica a Bogotá. Inauguración de la II Asamblea General de los obispos de América Latina. Homilía del Santo Padre Pablo VI», Vatican, 24 de agosto de 1968. 
tendencia comunitaria, por otra parte, le hace correr el peligro de encerrarse en pequeños grupos agresivos. ${ }^{62}$

Aunque la definición estaba atravesada por una perspectiva adultocéntrica y aleccionadora, el esfuerzo de la Iglesia católica por fabricar este concepto era inédito y sobresaliente. Si bien, el aparato erudito del texto referenciaba únicamente discursos papales, la elaboración conceptual evidenciaba un vocabulario apegado a los discursos tradicionales y políticos de ese contexto e influenciado por los principales aportes de las ciencias sociales de la época, aspecto que, según Bonnin, fue una de las características más notables de la Conferencia de Medellín. ${ }^{63}$ Temas como la marginalización de ese grupo etario, su rechazo por el pasado, el desacato a las autoridades, la simultaneidad de contextos de radicalización, su idealismo y sensibilidad frente a las coyunturas políticas, así como las disputas generacionales, eran centrales en los estudios sobre la juventud de esa área del conocimiento y guiaban las discusiones y políticas sobre las personas jóvenes. ${ }^{64}$ No obstante, las referencias sobre el extremismo, la radicalización y agresividad de los grupos juveniles sugiere ideas cargadas de un hondo sesgo anticomunista sobre las acciones políticas de la juventud, propias de un año como 1968, cuando una comunidad global de protestas protagonizadas por jóvenes caracterizaban muchos de los debates en el mundo entero. ${ }^{65}$

En esencia, lo más interesante de ese concepto era su amplitud. Si más tarde Juan Pablo II circunscribiría sus discursos sobre la juventud a las comunidades estudiantiles y universitarias, este las tomaba en cuenta, pero iba más allá, para pensar en las acciones, las agrupaciones y las problemáticas contextuales de un número más amplio de jóvenes y no se enfocaba solamente en el creciente, pero reducido, grupo de estudiantes de la región. ${ }^{66}$ En este sentido, antes de crear una propuesta que permitiera llevar a la acción política su concepto, los obispos evaluaron las estructuras eclesiásticas existentes hasta ese momento en América Latina y aceptaron que, a las juventudes, el jerarquizado mundo religioso del catolicismo les resultaba «a menudo extraño»: esperaban de los «pastores» mucho «mayor apoyo moral» en sus denuncias políticas, la puesta en práctica de las doctrinas religiosas y una vida más cercana a la pobreza. Asimismo, esa evaluación trataba de evidenciar una inquietud por las modalidades de agrupación

62 Consejo Episcopal Latinoamericano, La Iglesia en la actual..., 103-105.

63 Bonnin, Discurso político..., 141-145; Bonnin, «Las voces...», 18.

64 Cfr. José Antonio Pérez Islas, Mónica Valdéz González y María Herlinda Suárez Zozaya (coord.), Teorías sobre la juventud. Las miradas de los clásicos (Ciudad de México: Universidad Nacional Autónoma de México, 2008); Philippe Ariès, «Las edades de la vida», en: Ensayos de la memoria, 1943-1983 (Bogotá: Editorial Norma, 1995), 327-341.

65 Philipp Gassert y Martin Klimke (ed.), 1968. Memories and Legacies of a Global Revolt (Washington: German Historical Institute, 2009), 6.

66 Iván Molina Jiménez, «La composición social de los estudiantes universitarios en América Latina. El caso de la Universidad de Costa Rica (1950-1973)», Revista de Historia de América, n. ${ }^{\circ} 151$ (2015): 57-90, https://revistasipgh.org/index.php/rehiam/article/view/393. 
juvenil, tendiente — según el CELAM - a realizarse en grupos y comunidades con un rechazo expreso a las «organizaciones demasiado institucionalizadas». ${ }^{67}$

Con lo anterior, los obispos proponían la necesidad «de adoptar una actitud de diálogo con la juventud», de tener conocimiento de su realidad socio-religiosa y «de promover centros de investigación» sobre la participación juvenil. Así, en los documentos finales de Medellín, la jerarquía eclesiástica latinoamericana recomendó «desarrollar una auténtica pastoral de juventud $[. .$.$] en los$ sectores urbano y rural», presentar «el rostro de una Iglesia auténticamente pobre [y] comprometida en la liberación de [...] todos los hombres», capacitar a las juventudes con el fin de que asumieran su «responsabilidad social como cristianos en el proceso de cambio latinoamericano», tener en cuenta «la importancia de las organizaciones y movimientos católicos de la juventud», otorgar confianza y reconocer la «autonomía» de esas agrupaciones, formar a quienes asesoraban a la juventud y enfatizar en la importancia de ese sector social. Además, pensaban en favorecer «el encuentro, el intercambio y la acción en común de los movimientos y organizaciones juveniles católicas con otras instituciones de juventud» y alentar «las iniciativas de carácter ecuménico». ${ }^{68}$

Cuidadosamente, el texto elaborado por los obispos de América Latina dejaba claro dos aspectos trascendentales. En primera instancia, hacían oficial y público su interés por las juventudes del campo y las ciudades, y ese interés incluía conceptualizar a ese sector de la población, investigarlo e identificar sus principales problemáticas. En un segundo momento, al proponer la creación de una «pastoral de juventud», sembraron la semilla de una modalidad de agrupaciones juveniles que se extendería por toda la región, en la que las personas jóvenes encontrarían justamente en la Iglesia espacios de sociabilidad con la mediación de sacerdotes y personas que les «formarían» en la religión. Oficialmente, la Iglesia no proponía espacios o ideas radicalizadas, pero el mismo uso cuidadoso del lenguaje permitiría interpretaciones duales. Bonnin afirma que en el contexto en que fueron escritos los documentos finales, palabras como «liberación», bien podían significar «revolución socialista o liberación espiritual»; «pobreza de la Iglesia» podía referirse a una Iglesia incorporada a la pobreza, o bien, a una Iglesia humilde, y la referencia a las ideologías podía reforzar los nacionalismos o el antiimperialismo y la «Patria Grande»; en ese sentido, el discurso religioso y su carácter relevante en la región tenía un potencial emancipatorio en las juventudes. Agruparlas en la Iglesia podía desradicalizarlas o darles elementos para pensar su contexto político a la luz de la liberación y el compromiso con la pobreza. ${ }^{69}$

67 Consejo Episcopal Latinoamericano, La Iglesia en la actual..., 103-106.

68 Ibíd., 109-110.

69 Bonnin, «Las voces...», 18. 
Aún así, para 1968, las organizaciones juveniles patrocinadas y mediadas por adultos tenían una larga data. Sandra Souto Kustrín documenta que en Bélgica, Francia y España estas surgieron desde el siglo XIX para crear «juventudes respetables» tras la creación de la Juventud Católica — adscrita a la Asociación Católica - y el exitoso modelo de la Juventud Obrera Cristiana, pero estas agrupaciones no sumarían fuerzas hasta el período de entreguerras y su crecimiento definitivo fue hacia la década de $1960 .{ }^{70}$ Algo similar sucedió en América Latina. Las investigaciones preocupadas por el estudio de las juventudes católicas durante la Guerra Fría evidencian que hacia el ocaso de la década de 1960 y durante el decenio siguiente, las agrupaciones católicas de jóvenes crecieron e intercambiaron ideas sobre sus realidades, generando procesos de radicalización dentro y fuera de las Iglesias y relacionándose con distintas agrupaciones políticas conformadas por personas jóvenes. ${ }^{71}$

Esos procesos de radicalización eran más evidentes para enero de $1979 \mathrm{y}$ así lo expresaron los obispos cuando realizaron su tercera Conferencia General del CELAM en Puebla. Los documentos finales de ese encuentro estrechaban un vínculo entre el presente e imaginaban el porvenir. En su publicación, titulada «La evangelización en el presente y en el futuro de América Latina», dedicaron un amplio capítulo a manifestar una «opción preferencial por los jóvenes», donde ampliaron de manera considerable el concepto de juventud e insistieron en la necesidad de agruparla en la Iglesia. Así, la juventud de ese momento era comprendida en términos mucho más amplios: el texto presentó una situación general de las personas jóvenes e insistió en aspectos muy extendidos en los discursos adultocéntricos sobre la juventud, como su inconformismo, sus posiciones radicales, su rebeldía e idealismo; todo ello, junto a su insuficiente «preparación», les hacía proclives al «acoso» y «manipulación» de «diversas ideologías». Pero cuando el texto se focalizó en la juventud de América Latina innovó, porque pensó en especificidades locales y consideró la existencia de «jóvenes indígenas, campesinos, mineros, pescadores y obreros que, por su pobreza, se ven obligados a trabajar como personas mayores». Al hacer ese diagnóstico, el documento trató de delinear la relación que la juventud debía establecer con el catolicismo:

Existen jóvenes muy inquietos socialmente, pero reprimidos por los sistemas de gobierno; éstos buscan a la Iglesia como espacio de libertad para poder expresarse sin manipulaciones y poder protestar social y políticamente. Algunos, en cambio, pretenden utilizarla como instrumento de contestación [...] Los jóvenes deseosos de realizarse en la Iglesia, pueden quedar defraudados cuando no hay una buena

70 Sandra Souto Kustrín, «"El mundo ha llegado a ser consciente de su juventud como nunca antes”. Juventud y movilización política en la Europa de entreguerras», Mélanges de la Casa de Velázquez, 34, n. ${ }^{\circ} 1$ (2004), 179-215, https://journals.openedition.org/mcv/1190; Sandra Souto Kustrín, «Juventud, teoría e historia: la formación de un sujeto social y de un objeto de anaálisis», Historia Actual Online, n. ${ }^{\circ} 13$ (2007): 175, http://hdl.handle.net/10261/162771.

71 Alcántara Navarro, 50-60; Pensado, 156-192. 
planificación y programación pastoral que responda a la realidad histórica que viven [...] Queremos responder a la situación de la juventud, con los tres criterios de verdad propuestos por S. S. Juan Pablo II: la verdad sobre Jesucristo, la verdad sobre la misión de la Iglesia y la verdad sobre el hombre [... L La Iglesia confía en los jóvenes. Son para ella su esperanza. La Iglesia ve en la juventud de América Latina un verdadero potencial para el presente y el futuro de su evangelización. Por ser verdadera dinamizadora del cuerpo social y especialmente del cuerpo eclesial, la Iglesia hace una opción preferencial por los jóvenes en orden a su misión evangelizadora en el Continente. Por ello, queremos ofrecer una línea pastoral global: desarrollar, de acuerdo con la pastoral diferencial y orgánica, una pastoral de juventud que tenga en cuenta la realidad social de los jóvenes de nuestro continente; atienda a la profundización y al crecimiento de la fe para la comunión con Dios y con los hombres; oriente la opción vocacional de los jóvenes; les brinde elementos para convertirse en factores de cambio y les ofrezca canales eficaces para la participación activa en la Iglesia y en la transformación de la sociedad. ${ }^{72}$

Es claro que el documento no solamente establecía una crítica a los gobiernos «represivos» de la región, sino que les restó agencia a las juventudes y trató de presentar a la Iglesia como un lugar de protesta y de expresión de los malestares sociales. Para lograrlo, la Iglesia empezaría por canalizar las inquietudes juveniles hacia las fronteras de la religión y esas fronteras ya habían sido trazadas por su líder, quien, como se sabe, se había apegado a la bipolaridad de la Guerra Fría y buscaba la desradicalización de la juventud mediante una figura monolítica de las ideologías, de Cristo y de la juventud. Así, el documento tradujo las «pastorales juveniles» como movimientos juveniles que debían incorporarse al conjunto de las diócesis locales y nacionales y mediadas por la autoridad de un sacerdote, religioso o laico que contara con un proceso formativo para tratar con juventudes. Cada uno de estos movimientos debería de adaptarse según la composición social de las juventudes, pues los obispos sabían que las pastorales podían estar conformadas por «estudiantes de secundaria, universitarios, obreros, campesinos, que tienen condicionamientos propios y exigencias distintas»; sin embargo, cada movimiento debía de tener un proceso educativo estandarizado:

El fundamento de tal educación será la presentación al joven del Cristo vivo, Dios y Hombre, modelo de autenticidad, sencillez y fraternidad; único que salva liberando de todo pecado y sus consecuencias y compromete a la liberación activa de sus hermanos por medios no violentos [...] La pastoral de juventud ayudará también a formar a los jóvenes de un modo gradual, para la acción socio-política y el cambio de estructuras, de menos humanas en más humanas, de acuerdo con la Doctrina Social de la Iglesia. Se formará en el joven un sentido crítico frente a los medios de comunicación social y a los contravalores culturales que tratan de transmitirle las diversas ideologías, especialmente la liberal capitalista y la marxista, evitando así las manipulaciones. Se recomienda dar la mayor importancia a todos

72 Consejo Episcopal Latinoamericano, La evangelización en el presente y en el futuro de América Latina. Puebla: Conclusiones de la III Conferencia General del Episcopado Latinoamericano (Santiago: Conferencia Episcopal de Chile, 1979), 318-323. 
aquellos medios que favorecen la evangelización y el crecimiento en la fe: Retiros, Jornadas, Encuentros, Cursillos, Convivencias. ${ }^{73}$

Si en 1968 los obispos tenían la convicción de que las juventudes estaban excluidas y de que sentían inconformidad frente una Iglesia católica jerarquizada, en 1979 salieron al rescate de esa jerarquización y, aunque no comprendían a las juventudes solamente en su dimensión estudiantil, sí establecieron en las pastorales juveniles procesos de formación educativa que ya no pensaban únicamente en la pobreza y en el reconocimiento de la autonomía de los movimientos juveniles, tal y como lo habían hecho una década antes. Ahora, esos procesos educativos debían dirigirse hacia la formación de líderes políticos apegados a la doctrina, delimitar la «liberación» solamente hacia la figura de Cristo y por «medios no violentos»y trataban de evitar la «manipulación» del marxismo y del capitalismo mediante estrategias concretas; es decir, las pastorales juveniles eran uno de los mecanismos que debían conducir las inquietudes políticas de las personas jóvenes y, en adelante, a ese interés se sumarían los retiros espirituales, las jornadas, los encuentros de jóvenes y las convivencias, como nuevos espacios dentro de las sociabilidades juveniles y que moldearían las identidades de muchas de las personas que vivieron su juventud durante 1980 .

El cambio discursivo de la Iglesia católica latinoamericana es sobresaliente, pero comprensible. Juan Pablo II no solamente era el líder central de una institución transnacional, sino que era un anticomunista consciente de su poder, que asumió su cargo en un álgido contexto de la Guerra Fría. En enero de 1979, cuando los obispos del CELAM se reunieron en Puebla, Juan Pablo II les dirigió un amplísimo discurso de inauguración, donde les solicitaba «estar cerca» de las juventudes y aprovechar sus «energías». ${ }^{74}$ En ese mismo contexto, la insurrección sandinista en Nicaragua tenía algunos meses de haber iniciado y este proceso estaría caracterizado por una intensa participación de la Iglesia católica, por la lectura del contexto nicaragüense a la luz de las ideas de la Teología de la Liberación y por su composición primordialmente juvenil. Esa misma participación ha hecho que los estudios y las memorias sobre ese conflicto consideren que esta fue «la revolución de los muchachos» y de las muchachas, y que se piense que Centroamérica fue uno de los últimos escenarios de la Guerra Fría. ${ }^{75}$ Ese proceso

73 Ibíd., 324-325.

74 Juan Pablo II, «Discurso del Santo Padre Juan Pablo II en la inauguración de la III Conferencia General del Episcopado Latinoamericano», Vatican, 28 de enero de 1979.

75 Gérard Lutte, «La Revolución de los muchachos: los jóvenes en la Nicaragua Sandinista», en: La construcción histórica de la juventud en América Latina. Bohemios, rockanroleros \& revolucionarios, (ed.) Yanko González y Carles Feixa (Santiago: Editorial Cuartopropio, 2013), 407-455; Williams, 65-96; Gilles Bataillon, «Los "muchachos" en la revolución sandinista (Nicaragua, 1978-1980)», Estudios Sociológicos, 31, n. ${ }^{\circ} 92$ (2013): 303-343, https://estudiossociologicos.colmex.mx/index.php/es/article/view/63.; Sergio Ramírez Mercado, Adiós muchachos, (México: Alfaguara, 2007); John Swift, The palgrave concise historical atlas of the Cold War (Nueva York: Springer, 2003). 
político no solamente preocuparía a Juan Pablo II; él mismo se convertiría en opositor e intentaría utilizar su poder político para que este llegara a su fin. ${ }^{76}$

La misma coyuntura, junto a otros contextos latinoamericanos de radicalización juvenil, hacía que frente a otras personas jóvenes de la región, el papa pensara en las corrientes ideológicas e inmediatamente articulara un discurso que ya no apelaba a la «liberación» de América Latina como lo hacían los obispos en Medellín y que se detenía menos en la pobreza, para recuperar su propia experiencia juvenil en la Polonia de la posguerra, ignorar la capacidad de agencia de las muchachas y muchachos frente a sus propios contextos regionales y sugerirles no dejarse «instrumentalizar» por los discursos ideológicos que dividían el mundo y de los que él era portador y vocero transnacional. ${ }^{77}$

\section{Tarea prometedora: la juventud pastoral de Costa Rica}

En enero de 1980, el arzobispo de San José y presidente de la Conferencia Episcopal de Costa Rica, monseñor Román Arrieta Villalobos, escribió una evaluación de los acuerdos que él y sus colegas latinoamericanos habían firmado el año anterior en Puebla. Su interpretación, inédita durante poco más de un año y publicada en el Mensajero del Clero hasta marzo de 1981, recuperó los principales ejes temáticos de la tercera Conferencia General del CELAM y, con ellos, trazó el camino de la Iglesia costarricense en un artículo que ese rotativo oficial publicó con el título de «[i] Hacia dónde va la Iglesia Católica costarricense?».

En el texto, Arrieta Villalobos presentó la Conferencia en Puebla como el momento más importante para la Iglesia católica de la década de 1970, valoró positivamente su intento de pensar en el presente y el futuro de la región y afirmó que él y sus colegas costarricenses asumirían los cuatro grandes retos planteados en la reunión: la familia, las vocaciones sacerdotales, la pobreza y la juventud. Así, al referirse al último reto, el sacerdote escribió brevemente:

La opción por la juventud. Exigirá a la Iglesia Costarricense tomar iniciativas y sumar su esfuerzo a todo proycto [sic] encaminado a dar soluciones eficaces a los múltiples problemas que en orden moral, religioso, educativo, ideológico, etc. afectan a esa población mayoritaria de nuestra población y son causa o pretexto para que se aleje de Cristo y más que todo de la Iglesia como institución. Deberá la Iglesia hacer dos cosas en especial: acercarse más al mundo de los jóvenes: universitarios, obreros y campesinos, etc. y preparar sacerdotes y laicos para cumplir esta tarea nada fácil pero sumamente urgente y prometedora. ${ }^{78}$

En comparación con el amplio espacio que el obispo le dedicó al tema de la pobreza, otros como la familia, las vocaciones y la juventud no parecían

76 Weigel, 451-457.

77 Juan Pablo II, «Viaje apostólico a Brasil...», Vatican, 1 de julio de 1980.

78 Román Arrieta Villalobos, «[i]]Hacia dónde va la Iglesia Católica costarricense?», Mensajero del Clero, marzo de 1981, 16-17. El texto resaltado es del original. 
ser de tanta urgencia para él. Sin embargo, su referencia sobre la importancia demográfica de la juventud era una realidad en el país; solamente entre 1979 y 1980, las personas entre los 15 y los 29 años significaban alrededor de un treinta por ciento de la población total de Costa Rica. ${ }^{79}$ Pero, a pesar de que la «exigencia» de Arrieta Villalobos de «tomar iniciativas» que permitieran combatir los problemas «morales» e «ideológicos» que afectaban a las personas jóvenes era muy actual para 1980, esto ya había sido aplicado en la Iglesia católica de Costa Rica desde la década anterior: ¿Cuándo y cómo había sido aplicado este interés y cuáles razones motivaban que el obispo más influyente de Costa Rica recuperara el tema de la juventud en ese momento?

El Mensajero Eclesial, otra publicación periódica oficial del catolicismo costarricense así lo había informado entre marzo y abril de 1971, cuando monseñor Carlos Rodríguez Quirós, el antecesor de Arrieta Villalobos, creó una «Pastoral Orgánica de Juventudes y de Encuentros de Promoción Juvenil», que contaba con financiamiento económico, una estructurada organización de una docena de sacerdotes y «seglares» dedicados por completo al «apostolado juvenil» y que estaban dotados de «una completa libertad» e independencia de otras organizaciones eclesiásticas para cumplir con sus objetivos. ${ }^{80} \mathrm{Si}$ bien, es necesaria una investigación a profundidad para conocer la trayectoria de esta primera iniciativa, las organizaciones religiosas de las juventudes costarricenses ya existían desde la década de 1960 y algunas de ellas tenían un fuerte contenido político. En un estudio publicado en 1972, Luis Barahona Jiménez había identificado al menos quince organizaciones de jóvenes religiosos, compuestas en su mayoría por estudiantes urbanos de colegios y universidades. ${ }^{81}$

Por su parte, al explicar el surgimiento de los movimientos sociales adscritos al catolicismo de finales de la década de 1960, varios estudios han mencionado que tras el período de renovación transnacional que experimentó la Iglesia en el Concilio Vaticano II y luego de su lectura latinoamericana en Medellín, la reunión del CELAM en Puebla significó el restablecimiento de una política anticomunista y de un «autoritarismo jerárquico», acompañados del control ideológico de los movimientos católicos que habían surgido tras la reunión de 1968. Esencialmente, una de las nuevas preocupaciones de un sector del CELAM en 1979 fue el conflicto centroamericano, razón por la que algunos obispos le enviaron al papa un informe al respecto desde 1982; ese documento

79 Instituto Nacional de Estadística y Censos, Estimaciones y proyecciones de población por sexo y edad 1950-2050 (San José: Instituto Nacional de Estadística y Censos/Centro Centroamericano de Población, 2013), 23-30; véase, también: Iván Molina Jiménez, La educación en Costa Rica de la época colonial al presente (San José: Editoriales Universitarias Públicas Costarricenses, 2016), 353 y 447.

80 Carlos Rodríguez Quirós, «Decreto de Integración del Equipo de Pastoral Orgánica de Juventudes y de Encuentros de Promoción Juvenil», Mensajero Eclesial, marzo de 1971, 7 y 14; Mensajero Eclesial, «Nuestra Arquidiócesis se organiza en su Pastoral Juvenil», abril de 1971, 3-4.

81 Luis Barahona Jiménez, Juventud y política (San José: Ministerio de Cultura, Juventud y Deportes, 1972), 170-189. 
ha sido ubicado como uno de los antecedentes de su visita a Centroamérica, en marzo del año siguiente. ${ }^{82}$

Así, todo apunta a que la estructura de la pastoral juvenil costarricense de 1971 fue inventada frente a la cantidad de agrupaciones juveniles de contenido religioso que ya existían en el país y que el catolicismo buscaba institucionalizar; además, no cabe duda de que esta misma organización estaba inspirada en el apartado sobre la juventud de los documentos finales de Medellín, pues al tener «completa libertad», este primer mecanismo católico de agrupación juvenil en Costa Rica se apegaba al reconocimiento de la autonomía de los movimientos juveniles que habían establecido los obispos reunidos en 1968. Por el contrario, la nueva «exigencia» de Arrieta Villalobos, mucho más cercana a las discusiones de Puebla sobre la jerarquización de estas organizaciones, establecía la nueva manera en que tendrían que funcionar las pastorales juveniles en el país: carentes de esa libertad, mediadas por la autoridad adulta institucionalizada en la Iglesia y por procesos de aleccionamiento que acercaran a los jóvenes a Cristo, pero más que todo, a la institución católica.

Esto fue evidente en el contenido de una carta publicada por el obispo de Alajuela en el Mensajero del Clero de diciembre de 1980. Allí, monseñor Enrique Bolaños Quesada estableció las prioridades que tendrían las personas encargadas de las pastorales juveniles: para él, estas agrupaciones debían ser coordinadas con «prudencia», evitar el consumo de drogas en las juventudes universitarias, colegialas y trabajadoras mediante Cristo, el deporte y la recreación. ${ }^{83}$ Pero, ¿cómo y por qué razón se ejecutó esta preocupación en la Iglesia católica de Costa Rica? Poco tiempo después de conocer el informe de los obispos del CELAM sobre Centroamérica, Juan Pablo II anunció su visita a la región y el periódico La Nación dio a conocer oficialmente la noticia en su portada del 10 de diciembre de $1982 .{ }^{84}$

Todo apunta a que, junto con los acuerdos asumidos en Puebla, esta noticia fue un impulso definitivo de las pastorales juveniles en Costa Rica. Al menos así lo insinuó Contrapunto, el periódico quincenal del Sistema Nacional de Radio y Televisión que, en su edición del 16 de diciembre de 1982, informó sobre uno de los nuevos mecanismos de la Iglesia católica costarricense para agrupar a las juventudes del país: las «convivencias juveniles». Siguiendo al pie de la letra las instrucciones de Puebla y de Arrieta Villalobos, estas actividades eran organizadas por un sacerdote y un laico. De la información que ofrecieron sus encargados, Víctor Cordero Poveda y el padre Rómulo Emiliani Sánchez — quien décadas

82 Miguel Concha Malo, Óscar González Gari, Lino Salas y Jean-Pierre Bastian, La participación de los cristianos en el proceso popular de liberación en México (1968-1983) (Ciudad de México: Siglo XXI, 1986), 183-184.

83 Enrique Bolaños Quesada, «Mensaje Pastoral de Mons. Enrique Bolaños», Mensajero del Clero, diciembre de 1980, 33-34.

84 La Nación, «Obispos comunicaron a Monge visita del Papa», 10 de diciembre de 1982, 1A-2A. 
después se convertiría en obispo de San Pedro Sula, Honduras - es evidente que las convivencias juveniles eran espacios de sociabilidad ideados para aglutinar grandes grupos de jóvenes durante días completos y ofrecerles formación religiosa; ambos calculaban haber recibido ocho mil jóvenes e identificar riesgos juveniles como la prostitución, el alcoholismo, la drogadicción y la «brujería». Realizados mensualmente desde 1981, aseguraban hablar en un lenguaje sencillo sobre la familia, el pecado, el «libertinaje», el consumo y las drogas, y ponían énfasis en que la única liberación juvenil estaba en Cristo. ${ }^{85}$

Evidentemente, el apego discursivo que ambos dirigentes demostraban respecto al vocabulario de Juan Pablo II, al estrechar las temáticas juveniles con la liberación y el consumo de drogas, insinúa que el concepto monolítico de juventud elaborado por el papa fue puesto en práctica por algunos miembros de Iglesia en el país, donde ese concepto fue apropiado y llevado a la acción mediante tareas concretas como las convivencias que se realizaban y se anunciaban, de manera particularmente frecuente, en medios de prensa como el Eco Católico ${ }^{86}$ en adelante, otros sacerdotes y otras personas católicas emprenderían pastorales juveniles en sus propias parroquias y atenderían preocupaciones neurálgicas y transnacionales de la Iglesia como las drogas y la sexualidad, temáticas privilegiadas sobre otras que antes ocuparon más amplios espacios de discusión como la pobreza y las realidades políticas de las juventudes. ${ }^{87}$ Así, la visita del papa a Costa Rica y su reunión con la juventud intensificó estos mecanismos de organización en el país por parte de la Iglesia.

La multitud que recibió a Juan Pablo II en Costa Rica el 2 de marzo de 1983 fue sobresaliente y es muy posible que el país no demostrara tanta euforia por un invitado internacional desde la visita de John F. Kennedy al país. De manera similar a la estancia del presidente católico de los Estados Unidos en 1963, la llegada del papa puso a Costa Rica en la mira internacional y en un escenario propio de la Guerra Fría, al representar al país como un lugar central en la lucha transnacional contra el comunismo ${ }^{88}$ Costa Rica fue el lugar «seguro» donde Juan Pablo II durmió durante tres noches después de visitar Nicaragua y Panamá, y el único país de la región donde tuvo un encuentro con la juventud. ${ }^{89}$

85 Fabio Muñoz, «Las convivencias juveniles», Contrapunto, 16 de diciembre de 1982, 7; Eco Católico, «Convivencias juveniles misioneras», 17 de julio de 1983, 7.

86 Eco Católico, «Convivencias juveniles católicas», 19 de setiembre de 1982, 13; Eco Católico, «Convivencias juveniles católicas», 17 de octubre de 1982, 7 .

87 Fabio Muñoz, «Hablan sacerdotes y jóvenes creyentes: Dios con los jóvenes», Contrapunto, 1 de agosto de 1983, 14-15.

88 David Díaz Arias, «A los pies del águila: la visita de John F. Kennedy a Costa Rica en 1963», en: El verdadero anticomunismo. Política, género y Guerra Fría en Costa Rica (1948-1973), (ed.) Iván Molina Jiménez y David Díaz Arias (San José: Editorial de la Universidad Estatal a Distancia, 2017), 180-213.

89 La Nación, «Hoy llega el Santo Padre», 2 de marzo de 1983, 1A-17A; La Nación, «El Papa llega con mensaje de paz», 3 de marzo de 1983, 1A-19A; La Nación, «Histórico encuentro de fe», 4 de marzo de 1983, 1A-13A. 
La razón de esa excepcionalidad quedó explícita en esos días y en las evaluaciones sobre el discurso papal publicadas días más tarde en la prensa. Al hacer referencia a Centroamérica, esas evaluaciones rescataban el llamado del papa a la población costarricense a «ser files a vuestra tradición» y rechazar los «métodos de violencia» empleados en otros países. Las mismas evaluaciones rescataban la «esperanza» del papa en una juventud disciplinada, respetuosa y alegre como la costarricense, quien luego de condenar el consumo de drogas y el «desenfreno sexual», había enfatizado en Centroamérica para poner el futuro de la región en manos de los muchachos y las muchachas del país, a quienes presentaba como las únicas personas capaces de luchar contra el odio y la violencia y de «aleccionar» sobre el amor y la paz. ${ }^{90}$

En los meses y años siguientes a las palabras del papa en Costa Rica, el Eco Católico aumentó exponencialmente el número de referencias sobre la juventud. Durante toda la década de 1980, ese semanario publicó un centenar de notas al respecto y alrededor del treinta por ciento de ellas eran invitaciones a pastorales y convivencias. De la mano con los discursos transnacionales de la Iglesia sobre la juventud, la línea editorial del rotativo olvidó la reunión de obispos en Medellín y privilegió las referencias a la realizada en Puebla. Así, empezó a identificar a una juventud «respetable» y «positiva»: cargada de valores como la paz y que por su adscripción y vocación pastoral, estaba comprometida con la Iglesia, con sus valores tradicionales sobre la familia, la sexualidad, la educación y la religión, y cuyos espacios de sociabilidad se circunscribían a los ambientes eclesiásticos en los que rezaba por la paz y rechazaba la violencia frente al conflicto centroamericano. Pero el Eco Católico también identificó a una juventud contrapuesta, que corría peligros como el ateísmo, las agrupaciones sin orientación cristiana, el consumo, el odio, los vicios y la violencia. Esencialmente, de este ensayo de conceptualización de dos juventudes es particularmente interesante que ninguna establecía relaciones entre la etapa juvenil con la participación y las ideas políticas, circunscribiendo las buenas prácticas juveniles únicamente al campo de la praxis del catolicismo, ${ }^{91}$ donde las muchachas y muchachos

90 Eugenia Sancho, «Sencillez, candor, magnetismo... el carisma de Juan Pablo II», Contrapunto, 16 de marzo de 1983, 10; Tony Montes, «Gracias jóvenes ciudadanos», Eco Católico, 3 de julio de 1983, 5; La Nación, «Papa invita a jóvenes a luchar contra el odio y la violencia», 4 de marzo de 1983, 4A; Eco Católico, «Alocución a los jóvenes (Costa Rica, 3 de marzo) en el Estadio Nacional», 13 de marzo de 1983, 12-13. Cfr. Juan Pablo II, «Viaje apostólico a América Central. Discurso del Santo Padre Juan Pablo II a los jóvenes», Vatican, 3 de marzo de 1983.

91 Eco Católico, «Puebla: opción preferencial por los jóvenes», 12 de junio de 1983; José Castro Mora, «Jóvenes de Costa Rica, orad por la paz», Eco Católico, 17 de julio de 1983, 3; Eco Católico, «[¿i]Qué significa para nosotros la juventud?», 27 de enero de 1985, 7; Violeta Fallas Jiménez, «La educación religiosa y la juventud», 31 de marzo de 1985, 11; Gustavo Adolfo Monge Solano, «El joven y su obligación con la Iglesia», Eco Católico, 1 de junio de 1986, 11; Luis León Sáenz, «El potencial para la evangelización es la juventud», Eco Católico, 16 de junio de 1986, 3. 
costarricenses debían percatarse de las diferencias «ante las ideologías capitalistas y marxistas». ${ }^{92}$

En ese sentido, la elaboración más cuidadosa que hizo la Iglesia católica de Costa Rica del concepto de juventud fue durante la década de 1980. Ese concepto estaba totalmente permeado por el de paz y estrechaba tanto el límite entre ambos, que la paz era presentada como virtud y condición natural de la juventud. ${ }^{93}$ Lo interesante de este concepto es que su elaboración no empezó a manifestarse sino hasta 1984 y había sido en noviembre de 1983 cuando el presidente Luis Alberto Monge Álvarez (1982-1986) firmó la declaratoria de «neutralidad perpetua, activa y no armada» de Costa Rica frente al conflicto centroamericano en un intento por presentar al país como el único territorio centroamericano de paz. ${ }^{94}$ Además, este acontecimiento discursivo coincidió con la víspera del Año Internacional de la Juventud (1985) que la ONU desarrolló desde los ejes de "participación, desarrollo y paz». ${ }^{95}$

Si bien, el primer religioso en hacer la asociación entre paz y juventud fue Juan Pablo II, ${ }^{96}$ esos argumentos calaron en los discursos oficiales de la Iglesia católica de Costa Rica, que frente al contexto centroamericano podía presentar a las juventudes del país como un sector aislado de la región y como jóvenes que se habían permeado de los valores positivos de la religión. En ese sentido, el Año Internacional de la Juventud fue un momento propicio para que las páginas del Eco Católico insistieran en tales ideas y para que sacerdotes, obispos y laicos valoraran positivamente las pastorales juveniles. ${ }^{97}$ Para 1986, esas pastorales habían empezado a formar parte de un proyecto que los sacerdotes de la ciudad de San José fortalecieron mediante la creación de la Comisión Arquidiocesana de Pastoral Juvenil. Ubicada en el distrito universitario de San Pedro de Montes de Oca, la Comisión se encargaría de atender problemas de adicción, crear «casas

92 Fernando Muñoz Mora, «Toda pastoral juvenil es vocacional», Eco Católico, 5 de mayo de 1985, 6.

93 Eco Católico, «La paz y los jóvenes caminan juntos», 30 de diciembre de 1984, 3; Óscar Rodríguez Blanco, «La paz y los jóvenes caminan juntos», Eco Católico, 24 de febrero de 1985, 14.

94 Cortés Sequeira, 127-163; Díaz Arias, «Historia de un viraje...», 591-611; David Díaz Arias, «Enfrentar a Reagan y a la Contra: los intelectuales, opinión pública costarricense y la discusión por la paz en Centroamérica (1986-1987)», Memorias. Revista Digital de Historia y Arqueología desde el Caribe colombiano, 12, n. ${ }^{\circ} 30$ (2016): 188-218, http://dx.doi.org/10.14482/memor.30.9092.; David Díaz Arias, «Hegemonía imperial, diplomacia y Guerra Fría: los intelectuales costarricenses y la neutralidad perpetua, 1982-1986», Diálogos, 23, n. ${ }^{\circ} 1$ (2019): 151-179, https://doi.org/10.4025/dialogos.v23i1.46362.

95 Organización de las Naciones Unidas, «Resolución 40/14. Año Internacional de la Juventud: Participación, Desarrollo y Paz», United Nations, 15 de noviembre de 1985, 205-206. URL: https://www.un.org/es/ events/youthday/

96 Juan Pablo II, «La paz y los jóvenes caminan juntos: Mensaje de su Santidad Juan Pablo II para la celebración de la XVIII Jornada Mundial de la Paz», Vatican, 1 de enero de 1985.

97 Óscar Rodríguez, «Año Internacional de la Juventud», Eco Católico, 11 de noviembre de 1984, 13; Román Arrieta Villalobos, «Nuestra Arquidiócesis y el Año Internacional de la Juventud», Eco Católico, 17 de febrero de 1985, 2; Alexander Bonilla, «El Año Internacional de la Juventud», Eco Católico, 2 de junio de 1985, 12. 
de juventud», vínculos con otras agrupaciones y espacios de formación, enfatizando en la «opción por la juventud de Puebla». ${ }^{98}$

Además de ser replicada en zonas rurales del país y de motivar la creación de organizaciones como la «Asociación de Fieles Laicos, Familia y Juventud» - coordinada por Cordero Poveda—,${ }^{99}$ lo más interesante del surgimiento de esta Comisión es que, hacia el ocaso de la década de 1980, creó un vínculo discursivo y material inédito entre las organizaciones religiosas de la juventud costarricense, al presentarse como parte de una iniciativa latinoamericana y asistir a encuentros en diferentes países de la región. Así, en el encuentro de 1988, fueron establecidos los nuevos mecanismos de participación de las juventudes en la Iglesia, que demostraron una rígida estructuración elaborada por los sujetos adultos designados para dirigir a las juventudes católicas: cada pastoral debía contar con un proceso de «educación no formal» para «motivar» a la juventud, incluirla en una segunda etapa de formación y culminar en el proceso de «militancia». El uso del vocabulario político que adoptó la Iglesia de América Latina a fines de la década es interesante, pero aparte de las menciones relacionadas con la pobreza, este proceso de «latinoamericanización» de las juventudes católicas no estableció vínculos con las realidades juveniles de la región y la praxis se orientó en procesos formativos mediados por la autoridad de personas adultas y por un discurso oficial que no hacía explícito el contexto político, que hablaba de la pobreza de manera desradicalizada y privilegiaba públicamente el argumento construido por el papa sobre el objetivo de las pastorales juveniles: la construcción futura de una «civilización del amor». ${ }^{100}$

En un amplio estudio sobre la Iglesia católica costarricense de la segunda mitad del siglo XX, Miguel Picado Gatjens propone que la institución pasó de tener un estrecho compromiso con la sociedad durante la primera mitad del siglo $\mathrm{XX}$, a una visión dualista durante los años siguientes, en la que la mayoría de los obispos y sacerdotes se separaron de las problemáticas socioeconómicas del país para dedicarse a los «asuntos espirituales». En ese sentido, el historiador evidencia que, junto a las pastorales juveniles, la Iglesia costarricense de la segunda mitad del siglo XX vio la proliferación de una sobresaliente cantidad de pastorales y agrupaciones de diversas tendencias eclesiásticas que iban desde organizaciones comunales hasta otras de composición obrera con francas preocupaciones

98 Mensajero del Clero, «Proyecto Pastoral basado en el V Sínodo Arquidiocesano», abril de 1986, 6-19; Eco Católico, «Para una pastoral juvenil arquidiocesana», 17 de enero de 1988, 16.

99 Archivo Histórico Arquidiocesano «Monseñor Bernardo Augusto Thiel», Asociación de Fieles, Laicos y Familia (San José: Ministerio Laico Familia y Juventud, 1988), 1-11; Eco Católico, «Salve Iglesia joven, esperanza de América Latina», 11 de junio de 1989, 12.

100 Eco Católico, «Costa Rica y la pastoral juvenil latinoamericana», 20 de noviembre de 1988, 10. 
sobre la función social del catolicismo frente a las realidades políticas y las crisis del país. ${ }^{101}$

Mediante la presentación de algunos casos, Picado Gatjens también evidencia que esas organizaciones compuestas por laicos y sacerdotes han tenido tres claras tendencias: una de tipo conservadora, una socialdemócrata y otra ligada a los movimientos populares. Así, él mismo ha demostrado que mientras organizaciones de tipo conservador tendientes a promover la «regeneración moral» lograron desarrollarse de manera extraordinaria al no perjudicar los intereses políticos de las élites costarricenses, existieron otras organizaciones preocupadas por temas laborales y sindicales y por la puesta en práctica de la «doctrina social de la Iglesia» que toparon con obstáculos de todo tipo y que la misma jerarquía eclesiástica movilizó esfuerzos para su supresión. Uno de esos casos fue el de la Juventud Obrero Católica, vista como un espacio de radicalización juvenil por las autoridades religiosas anticomunistas del país. La propuesta del historiador es interesante, porque permite interpretar el surgimiento, proliferación y apoyo que la jerarquía religiosa le ofreció a emprendimientos morales como las pastorales juveniles, que por su estructura y organización tendían a impedir los procesos de radicalización. Publicado en el ocaso de la década de 1980, este es un estudio con perspectiva de crisis: el país recién había experimentado una de sus peores coyunturas económicas y la jerarquía eclesiástica temía que la Revolución sandinista provocara una expansión de las escasamente extendidas Comunidades Eclesiales de Base, de una Iglesia popular costarricense y de la radicalización de las juventudes. ${ }^{102}$

Indudablemente, iniciativas como estas tenían el objetivo de sostener una relación estrecha y armónica entre la Iglesia y el Estado. En décadas previas, la jerarquía eclesiástica empezó a crear espacios para las juventudes universitarias posicionadas dentro de los límites del patriotismo costarricense, ${ }^{103}$ que protestaban con respeto a sus autoridades institucionales, ${ }^{104}$ que sostenían posiciones anticomunistas y expresaban su rechazo a procesos transnacionales de la Guerra Fría como la Revolución cubana. ${ }^{105}$ Pero al mismo tiempo, sectores juveniles del mundo religioso, universitario, obrero y sindical demandaban sin éxito una mayor participación de la Iglesia y una postura pública en favor de las luchas

101 Miguel Picado Gatjens, La Iglesia costarricense entre el Pueblo y el Estado: de 1949 a nuestros días (San José: Ediciones Guayacán, 1990), 21-26.

102 Ibíd., 139-141; 179-191 y 265-275.

103 Scarlett Aldebot-Green, The politics of Youth Citizenship in Costa Rica, 1940's -1980's. (Tesis de Doctorado en Historia, Universidad de California, 2014), 157-158.

104 Randall Chaves Zamora, «¿Un 68 imaginado? Juventud, identidad y memoria en América Latina: el caso del movimiento estudiantil en Costa Rica (1968-2018)», en: ¡Aquí los jóvenes! Frente a las crisis, (ed.) Gerardo Gutiérrez Cham y Olaf Kaltmeier (Guadalajara: Editorial de la Universidad de Guadalajara, 2019), 265-282.

105 Marco Garita Mondragón, «La Revolución Cubana y el movimiento estudiantil costarricense (19591962)», (San José: Inédito, 2018). 
políticas de los sectores marginalizados de la sociedad costarricense, todo esto con la inspiración socialista de organizaciones, sacerdotes y laicos radicalizados del país. ${ }^{106}$ Por ejemplo, se sabe que, en zonas rurales, algunos sacerdotes se incluyeron en luchas campesinas y obreras; en otros lugares como San Ignacio de Acosta se establecían procesos pastorales inspirados en el Concilio Vaticano II y en los documentos de Medellín; en La Aurora de Heredia se habían formado agrupaciones similares a las Comunidades Eclesiales de Base e, inclusive, en el distrito capitalino de Paso Ancho se habían desarrollado las mismas Comunidades y una organización juvenil llamada «Movimiento Juvenil de Paso Ancho», que por sus ideales, fue acusada de ser un grupo guerrillero que se preparaba para unirse a insurrecciones armadas en Honduras y El Salvador. ${ }^{107}$

Ciertamente, como cualquier otro sector juvenil, el del catolicismo no es representativo para «toda» la juventud del país, pero todo apunta a que este sector agrupó a una cantidad sobresaliente de jóvenes. También es cierto que durante la década de 1980 surgieron otros movimientos juveniles políticamente radicalizados. Así, las referencias mínimas que los discursos religiosos hacían, en sus medios oficiales de prensa y en sus documentos públicos, sobre la realidad política de Costa Rica, se trasladaron a las organizaciones juveniles de la institución, con lo cual se creó una conceptualización y una representación juvenil mucho más preocupada por su espiritualidad que por su materialidad. Consecuentemente, las vagas referencias al contexto político del país insinuaban la existencia de una juventud únicamente pastoral y aislada del conflicto centroamericano, en un país que se había construido internacionalmente como pacífico y con un énfasis discursivo excepcional.

Así, aunque el contexto costarricense de ese período de la Guerra Fría no puede homologarse al de otros países de Latinoamérica y Centroamérica, lo cierto es que en los albores de la década de 1980 se desarrollaban en Costa Rica procesos de radicalización juvenil ampliamente conocidos, que fueron intensamente discutidos en esos años y frente a los que la Iglesia no se manifestó en sus medios oficiales. Uno de ellos inició desde finales del decenio de 1970, cuando miles de jóvenes costarricenses tomaron las armas y se unieron a los movimientos de solidaridad con la Revolución sandinista; ${ }^{108}$ otro alcanzó su fin en 1981, cuando una célula guerrillera formada en el país inició sus actividades políticas

106 Pablo Richard y Guillermo Meléndez, La Iglesia de los pobres en América Central (San José: Departamento Ecuménico de Investigaciones, 1982), 251-300.

107 Picado Gatjens, La Iglesia costarricense..., 263-193; Bernardo Bolaños Esquivel y Manfred Quesada Méndez, El conflicto de la Hacienda Juan Viñas (1977): de lo laboral a lo político (Limón: Sede del Atlántico de la Universidad de Costa Rica, 2018).

108 Sofĩa Cortés Sequeira, Entre la esperanza y la desilusión: la izquierda costarricense y la Nicaragua sandinista (1983-1993) (Tesis de Maestría Académica en Historia, Universidad de Costa Rica, 2018); Adrián Jaén España, Movimientos sociales y solidaridad politica: la participación de la izquierda costarricense en la Revolución Sandinista (Tesis de Maestría en Ciencias Sociales, Facultad Latinoamericana de Ciencias Sociales, 2013). 
que acabaron con el encarcelamiento y muerte de algunos de sus militantes. ${ }^{109}$ Finalmente, entre 1980 y 1982, estudiantes del Instituto Tecnológico de Costa Rica realizaron el proceso de huelgas universitarias más extenso de la historia costarricense, que presentó momentos de represión policial, pero que dio como resultado la democratización de ese centro de estudios. ${ }^{110}$

Asimismo, el énfasis excepcional de la juventud costarricense no solamente fue una construcción de la Iglesia católica. Una idea similar sería presentada en 1989 por el sociólogo guatemalteco Edelberto Torres-Rivas cuando, al evaluar a las juventudes de Centroamérica, presentó a la de Costa Rica como «apática»y desposeída de compromisos políticos. ${ }^{111}$ Sin embargo, una evaluación como esta no tomaba en cuenta el contexto de crisis económica, el auge del neoliberalismo en el país e ignoraba los procesos de radicalización señalados, además de obviar el papel protagónico de la Iglesia en la consolidación de identidades mediadas por pastorales en las que las juventudes tuvieron una agencia política condicionada por sus autoridades religiosas. David Díaz Arias señala que la evaluación hecha por Torres-Rivas tampoco tomaba en cuenta los esfuerzos del gobierno de Costa Rica por crear nuevas identidades juveniles que buscaban moldear una imagen no radical de la juventud. En esa línea, él explica que el presidente Rodrigo Carazo Odio (1978-1982) le dio un protagonismo central a la juventud durante momentos tan importantes para la representación democrática del país como sus celebraciones patrias; en esas fiestas y en ausencia de instituciones militares, el presidente representaba a la juventud como el ejército de Costa Rica y la imaginaba como representativa del futuro. Pero al darle centralidad en esos espacios, también la representaba como un grupo social importante en la actualidad. ${ }^{112}$

No obstante, después de Carazo Odio vendría el gobierno de Monge Álvarez, cuya visión de la juventud incluyó la censura de algunas expresiones culturales y que seguiría a su antecesor, al pensar en la juventud como un ejército, pero

109 David Díaz Arias, «El Crimen de Viviana Gallardo», en: Ahi me van a matar. Cultura, violencia y Guerra Fría en Costa Rica (1970-190), (ed.) Iván Molina Jiménez y David Díaz Arias (San José, Costa Rica: Editorial de la Universidad Estatal a Distancia, 2018), 79-126; Eduardo Rey Tristán, «Guerrilla o terrorismo. El debate en torno a la caracterización de algunas organizaciones revolucionarias a partir del caso de La Familia», Diálogos. Revista Electrónica de Historia, 9, n. ${ }^{\circ}$ especial (2008): 4168-4188.

110 Iván Molina Jiménez, Huelgas democratizadoras: la rebelión estudiantil en el Instituto Tecnológico de Costa Rica (1980-1982) (San José, Costa Rica: Centro de Investigaciones Históricas de América Central y Editoriales Universitarias Públicas Costarricenses, 2019); Iván Molina Jiménez, «La huelga estudiantil de 1982 y la democratización del Instituto Tecnológico de Costa Rica», Diálogos, 23, n. . 1, (2019): 130-150, https://doi.org/10.4025/dialogos.v23i1.45253; Iván Molina Jiménez, «Párvulos guerrilleros. Las huelgas estudiantiles de 1980 en el Instituto Tecnológico de Costa Rica», Diálogos. Revista Electrónica de Historia, 19, n. ${ }^{\circ} 2$ (2018): 1-35, https://doi.org/10.15517/dre.v19i2.32283.

111 Edelberto Torres Rivas (ed.), Escépticos, rebeldes, narcisos: seis estudios sobre la juventud (San José, Costa Rica: FLACSO, 1989), 16.

112 David Díaz Arias, «Hijos de la crisis: la juventud costarricense de la década perdida (1978-1990)», en: La inolvidable edad. Jóvenes en la Costa Rica del siglo XX, (ed.) Iván Molina Jiménez y David Díaz Arias (San José, Costa Rica: EUNA, 2018), 135-153. 
ahora como un ejército real que protegería a Costa Rica de la Nicaragua sandinista. En ese sentido, cuando Óscar Arias Sánchez (1986-1990) asumió la presidencia del país, cambió su énfasis sobre la juventud y la imaginó en el porvenir, contribuyendo a la reconciliación, al desarrollo, a la reconstrucción y a la paz de la región. Además de la insistencia en el futuro, estos gobiernos buscaron alejar a las juventudes de las tendencias políticas radicales y, para ello, enfatizaban en temas como la ruralidad, el deporte y el uso de espacios públicos con un contenido discursivo que pensaba menos en la agencia de la juventud y más en cómo transformarles en agentes del Estado. De esa forma, el examen de Díaz Arias es claro en ubicar contextualmente a esa generación de jóvenes en medio de una crisis económica y como objetos de discursos conservadores sobre la sociedad; según él, la radicalización tenía menos sentido que «la lucha diaria por seguir siendo jóvenes en una década que se empeñó en convertirlos en adultos». ${ }^{113}$

Es sobresaliente que, en ese contexto de crisis, el futuro no solamente era incierto, sino que era la única herencia que el discurso de algunos políticos y de la Iglesia católica le ofrecía a las juventudes. Como se sabe, la tremenda insistencia de Juan Pablo II en definir a la juventud como portadora del porvenir y como vehículo de la paz fue replicada en Costa Rica por el catolicismo. Eso es interesante, si se toma en cuenta que ese mismo eje discursivo sería utilizado por figuras costarricenses tan importantes para los acuerdos de paz de la región centroamericana como Arias Sánchez, porque en conjunto con la Iglesia costarricense e internacional, el discurso y los conceptos desradicalizados, junto a la excepcionalidad y mecanismos como las pastorales juveniles, dejarían progresivamente de pensar en la juventud como un lugar de la memoria para convertirla en lugar del futuro y de la paz.

\section{Conclusiones}

La mañana del 23 de marzo de 1986, Juan Pablo II ofreció una misa a las juventudes de algunos lugares del mundo que habían llegado hasta el Vaticano para participar de la primera Jornada Mundial de la Juventud. La multitud juvenil que había llegado hasta Roma atendía la convocatoria global hecha por el papa y que, en adelante, sería desarrollada cada dos años en diferentes lugares del planeta. En medio de la misa, cuando Juan Pablo II ofreció su discurso, aclaró que ese día iniciaba una «tradición» a la que estaba invitada la Iglesia católica de todo el mundo; según él, esa tradición había sido inventada para satisfacer la necesidad las nuevas generaciones, que buscaban una «esperanza que no decepciona». ${ }^{114}$ Ciertamente, esa esperanza estaba cargada de un contenido divino y ese mismo contenido llenaba el concepto católico sobre la juventud. Más tarde,

113 Ibíd., 158-160.

114 Juan Pablo II, «Primera Jornada Mundial de la Juventud. Homilía del Santo Padre Juan Pablo II», Vatican, 23 de marzo de 1986. 
cuando volvió a dirigirse hacia quienes estaban en Roma, evidenció otro elemento que motivaba la actividad juvenil, al aclarar que ese año había sido declarado por la ONU como el Año de la Paz Internacional. ${ }^{115}$

Al darle sentido a su discurso mediante una idea cimentada en el futuro como la esperanza y poner a la paz junto a ella, los discursos del papa durante la primera Jornada Mundial de la Juventud sintetizaron la forma en que esa institución había definido a las juventudes durante la Guerra Fría. Si bien, la juventud de la Iglesia era su actualidad, sus identidades siempre fueron proyectadas en una promesa divina de un futuro de paz y esperanza. En abril de 1986, cuando estas ideas llegaron a Costa Rica, el Eco Católico trató de interpretarlas a la luz del próximo milenio: el rotativo imaginó esa actividad como una preparación hacia el año 2000, como el rejuvenecimiento de la Iglesia y como su servicio para el porvenir. Al fin, la tradición que había inventado el papa hacía que la Iglesia costarricense representara a la juventud como la portadora del nuevo milenio y como un sector que tenía una conciencia renovada y sensibilidad frente a los cambios. ${ }^{116}$

Ciertamente, para el caso de Costa Rica, no existe evidencia empírica generada oficialmente por la Iglesia católica que permita afirmar la existencia de una preocupación institucional por las juventudes radicalizadas del país o de la región; pero una investigación que tome en cuenta documentación no oficial, memorias, testimonios de protagonistas y otras experiencias parroquiales, podría evidenciar la existencia de focos comunales y experiencias de radicalización similares a otros contextos de Centroamérica y América Latina. Junto a esto, tales experiencias podrían evidenciar que, además de la visión desradicalizada sobre la juventud que articularon las jerarquías eclesiásticas, existieron otras formas de comprender este sector de la sociedad.

Así, este texto buscó hacer un primer acercamiento a la temática señalada, pero también espera ser un insumo inicial para pensar en el papel que jugó la Iglesia católica en la definición de las múltiples identidades juveniles que surgieron durante la Guerra Fría en un país como Costa Rica. Indudablemente, las jerarquías de la Iglesia costarricense no se detuvieron en discursos sobre la radicalización política y frente al contexto de agitación y violencia que vivía Centroamérica, el énfasis estuvo puesto en demostrar que Costa Rica era un territorio pacífico gracias a la mansedumbre de sus jóvenes.

Aunque el énfasis en las juventudes lo puso el Concilio Vaticano II, fueron los obispos de América Latina quienes hicieron que esta temática tomara un rol central dentro del catolicismo. Desde una perspectiva progresista y desde otra más conservadora, estas fueron coyunturas críticas para que un hombre tan importante como Juan Pablo II, creara una reunión global dedicada a la juventud. Es claro que en esa decisión operó una influencia descentrada: para inventar esa 
tradición, el líder anticomunista de la institución religiosa más poderosa de occidente, tomó las ideas de sus colegas latinoamericanos y creó el emprendimiento moral de la Jornada Mundial de la Juventud. ${ }^{117}$ Pero tal y como lo hicieron los políticos costarricenses durante la década de 1980, la Iglesia católica de muchas partes del mundo y sus jerarquías costarricenses representaron a la juventud desde una mirada conservadora y como un horizonte de expectativas: el concepto, ciertamente fue moldeado desde el presente, pero su sentido se encontraba en el porvenir. ${ }^{118}$ Así, la juventud no era un sector de la población que tuviera posibilidades de operar en su actualidad, sino que podía hacerlo solamente en el futuro, cuando sus identidades juveniles fueran cosa del pasado.

\section{Bibliografía}

Acosta Franco, Marisol. «Jóvenes de Medellín, nuevos actores sociales, 19601970». Pensar Historia. Revista de Estudiantes de Historia, n. ${ }^{4}$ (enero-junio, 2014): 21-36. Disponible en: http://bibliotecadigital.udea.edu. co/bitstream/10495/6119/1/AcostaYirla_2014 JovenesMedellinActores. pdf.

Acevedo Tarazona, Álvaro y Adrián Delgado Díaz. «Teología de la liberación y pastoral de la Liberación: entre la solidaridad y la insurgencia». Anuario de Historia Regional y de las Fronteras, 17, n. ${ }^{\circ} 1$ (enero-junio, 2012): 245-268. https://revistas.uis.edu.co/index.php/anuariohistoria/article/ view/2723.

Alcántara Navarro, Mónica. «El Consejo Hispanoamericano de Estudiantes (1979-1980). La juventud católica intransigente en la Guerra Fría». Páginas. Revista Digital de la Escuela de Historia, 11, n. ${ }^{\circ} 25$ (2019): 50-60. http://hdl.handle.net/2133/15038.

Antoniu, Bogdan. «The Origins of the Cold War a Historiographical Review». Euro-Atlantic Studies, n. ${ }^{\circ} 3$ (2000): 33-46. https://www.ceeol.com/search/ article-detail?id=648402.

Aldebot-Green, Scarlett. The politics of Youth Citizenship in Costa Rica, 1940's-1980's. Tesis de Doctorado en Historia, Universidad de California, 2014.

Alejos Grau, Carmen José. «América Latina en el siglo XX: religión y política». Studia et Documenta: rivista dell'Istituto Storico San Josemaría Escrivá, n. ${ }^{\circ} 11$ (2017): 19-47. https://www.isje.org/es/studia-et-documenta-3/ numeros-publicados/vol-11-2017/.

Archivo Histórico Arquidiocesano «Monseñor Bernardo Augusto Thiel». Asociación de Fieles, Laicos y Familia. San José: Ministerio Laico Familia y Juventud, 1988. 
Ariès, Philippe. «Las edades de la vida», en: Ensayos de la memoria, 1943-1983. Bogotá, Colombia: Editorial Norma, 1995.

Arrieta Villalobos, Román. «[i]Hacia dónde va la Iglesia Católica costarricense?». Mensajero del Clero, marzo de 1981, 16-17.

. «Nuestra Arquidiócesis y el Año Internacional de la Juventud». Eco Católico, 17 de febrero de 1985, 2.

Barahona Jiménez, Luis. Juventud y política. San José, Costa Rica: Ministerio de Cultura, Juventud y Deportes, 1972.

Bataillon, Gilles. "Los "muchachos" en la revolución sandinista (Nicaragua, 1978-1980)». Estudios Sociológicos, 31, n. ${ }^{\circ} 92$ (2013): 303-343. https:// estudiossociologicos.colmex.mx/index.php/es/article/view/63.

Becker, Howard. Outsiders: Studies in the Sociology of Deviance. Nueva York, EE. UU.: The Free Press, 1963.

Blaney, Joseph y Joseph Zompetti (ed.). The rhetoric of Pope John Paul II. Nueva York, EE. UU: Lexington Books, 2009.

Bolaños Esquivel, Bernardo y Manfred Quesada Méndez. El conflicto de la Hacienda Juan Viñas (1977): de lo laboral a lo político. Limón: Sede del Atlántico de la Universidad de Costa Rica, 2018.

Bolaños Quesada, Enrique. «Mensaje Pastoral de Mons. Enrique Bolaños». Mensajero del Clero, diciembre de 1980, 33-34.

Bonilla, Alexander. «El Año Internacional de la Juventud». Eco Católico, 2 de junio de 1985, 12.

Bonnin, Juan Eduardo. Iglesia y democracia. Táctica y estrategia en el discurso de la Conferencia Episcopal Argentina (1981- 1990). Berlín, Alemania: Editorial Académica Española, 2011.

—. Discurso político y discurso religioso en América Latina. Leyendo los borradores de Medellín (1968). Buenos Aires, Argentina: Santiago Arcos Editor, 2013.

- «Las voces de la Teología de la Liberación en los borradores de los Documentos Finales de Medellín (1968)». Bocadesapo. Revista de Arte, Literatura y Pensamiento, 12, n. ${ }^{\circ} 10$ (2011): 16-21. http://hdl.handle. net/11336/5908.

—. «Dinámicas de la voz y producción de legibilidad en los Documentos Finales de Medellín (1968). Un análisis genético-discursivo». Revista Latinoamericana de Estudios del Discurso, 10, n. ${ }^{\circ} 2$ (2010): 7-28. http:// dx.doi.org/10.35956/v.10.n2.2010.p.7-28.

Bourdieu, Pierre. «La "juventud" no es más que una palabra». En: Sociología y cultura, (ed.) Pierre Bourdieu. México, D.F.: Grijalbo, 2002.

Calvo Isaza, Óscar y Mayra Parra Salazar. Medellín (rojo) 1968. Bogotá: Editorial Planeta, 2012. 
Castro Mora, José. «Jóvenes de Costa Rica, orad por la paz». Eco Católico, 17 de julio de 1983, 3.

Chávez, Joaquín. «The University for Social Change and the Legacy of Ignacio Martín-Baró, S. J.». Peace and Conflict: Journal of Peace Psychology, 18, n. 1 (2012): 68-76. https://doi.org/10.1037/a0026866.

—. "Catholic Action, the Second Vatican Council, and the Emergence of the New Left in El Salvador (1950-1975)». The Americas, 70, n. 3 (2014): 459-487. https://doi.org/10.1017/S0003161500003990.

Chaves Zamora, Randall. Fuimos jóvenes: historia y memoria de las manifestaciones estudiantiles contra ALCOA en Costa Rica, (1968-2018). Tesis de Maestría Académica en Historia, Universidad de Costa Rica, 2018.

—. «¿Un 68 imaginado? Juventud, identidad y memoria en América Latina: el caso del movimiento estudiantil en Costa Rica (1968-2018)». En: ¡Aquí los jóvenes! Frente a las crisis, (ed.) Gerardo Gutiérrez Cham y Olaf Kaltmeier. Guadalajara, México: Editorial de la Universidad de Guadalajara, 2019.

Collins, Peter M. A Twentieth-Century Collision: American Intellectual Culture and Pope John Paul II's Idea of a University. Maryland: University Press of America, 2010.

Concha Malo, Miguel, Óscar González Gari, Lino Salas y Jean-Pierre Bastian. La participación de los cristianos en el proceso popular de liberación en México (1968-1983). México, D.F.: Siglo XXI Editores, 1986.

Consejo Episcopal Latinoamericano. La Iglesia en la actual transformación de América Latina a la luz del Concilio. II Conferencia General del Episcopado Latinoamericano. Bogotá: Secretariado General del Consejo Episcopal Latinoamericano, 1970.

- III Confrerencia General del Episcopado Latinoamericano. Documento de Puebla. México: Secretariado General del Consejo Episcopal Latinoamericano, 1978.

- La evangelización en el presente y en el futuro de América Latina. Puebla: Conclusiones de la III Conferencia General del Episcopado Latinoamericano. Santiago: Conferencia Episcopal de Chile, 1979.

Cortés Sequeira, Sofía. «Izquierda y neutralidad perpetua (1983-1984)». En: Ahi me van a matar. Cultura, violencia y Guerra Fría en Costa Rica (1970190), (ed.) Iván Molina Jiménez y David Díaz Arias. San José, Costa Rica: EUNED, 2018.

—. Entre la esperanza y la desilusión: la izquierda costarricense y la Nicaragua sandinista (1983-1993). Tesis de Maestría Académica en Historia, Universidad de Costa Rica, 2018. 
Cuartas, Carlos Julio. «La idea de universidad en Juan Pablo II». Theologica Xaveriana, n. ${ }^{\circ} 146$ (2003): 163-189. https://revistas.javeriana.edu.co/index. $\mathrm{php} /$ teoxaveriana/article/view/20884.

de Roux López, Rodolfo. «Los inciertos parajes de una nueva geografía religiosa en América Latina». L'ordinaire latino-américain, $\mathrm{n} .^{\circ}$ 200-201 (2005): 61-70.

Díaz Arias, David. «Historia de un viraje: la "neutralidad perpetua", la administración Monge Álvarez y la desigual construcción de la opinión pública en Costa Rica, 1982-1986». En: Historia de las desigualdades sociales en América Central. Una visión interdisciplinaria, siglos XVII-XXI, (ed.) Ronny Viales Hurtado y David Díaz Arias. San José, Costa Rica: CIHAC, 2016. «Enfrentar a Reagan y a la Contra: los intelectuales, opinión pública costarricense y la discusión por la paz en Centroamérica (1986-1987)». Memorias. Revista Digital de Historia y Arqueología desde el Caribe colombiano, 12, n. ${ }^{\circ} 30$ (2016): 188-218. http://dx.doi.org/10.14482/memor.30.9092. «A los pies del águila: la visita de John F. Kennedy a Costa Rica en 1963». En: El verdadero anticomunismo. Política, género y Guerra Fría en Costa Rica (1948-1973), (ed.) Iván Molina Jiménez y David Díaz Arias. San José, Costa Rica: EUNED, 2017.

. «El Crimen de Viviana Gallardo». En: Ahí me van a matar. Cultura, violencia y Guerra Fría en Costa Rica (1970-190), (ed.) Iván Molina Jiménez e David Díaz Arias. San José, Costa Rica: ENUED, 2018.

. «Hijos de la crisis: la juventud costarricense de la década perdida (19781990)». En: La inolvidable edad. Jóvenes en la Costa Rica del siglo XX, (ed.) Iván Molina Jiménez y David Díaz Arias. San José, Costa Rica: EUNA, 2018.

—. «Hegemonía imperial, diplomacia y Guerra Fría: los intelectuales costarricenses y la neutralidad perpetua, 1982-1986». Diálogos, 23, n. ${ }^{\circ} 1$ (2019): 151-179. https://doi.org/10.4025/dialogos.v23i1.46362.

Eco Católico. «Convivencias juveniles católicas», 19 de setiembre de 1982, 13. Eco Católico. «Convivencias juveniles católicas», 17 de octubre de 1982, 7.

Eco Católico. «Alocución a los jóvenes (Costa Rica, 3 de marzo) en el Estadio Nacional», 13 de marzo de 1983, 12-13.

Eco Católico. «Puebla: opción preferencial por los jóvenes», 12 de junio de 1983. Eco Católico. «La paz y los jóvenes caminan juntos», 30 de diciembre de 1984, 3. Eco Católico. «[i]Qué significa para nosotros la juventud?», 27 de enero de 1985, 7.

Eco Católico. «La Jornada Mundial de la Juventud Católica, 1986», 27 de abril de 1986, 4.

Eco Católico. «Para una pastoral juvenil arquidiocesana», 17 de enero de 1988, 16. 
Eco Católico. «Costa Rica y la pastoral juvenil latinoamericana», 20 de noviembre de 1988, 10.

Eco Católico. «Salve Iglesia joven, esperanza de América Latina», 11 de junio de 1989, 12.

Eco Católico. «Convivencias juveniles misioneras», 17 de julio de 1983, 7.

Faletto Verné, Enzo. «La juventud como movimiento social en América Latina». Revista de la CEPAL, n. ${ }^{\circ} 29$ (1986): 185-191.

Fallas Jiménez, Violeta. «La educación religiosa y la juventud», 31 de marzo de 1985, 11.

Garita Mondragón, Marco. «La Revolución Cubana y el movimiento estudiantil costarricense (1959-1962)». San José, Costa Rica: Inédito, 2018.

Gassert, Philipp y Martin Klimke (ed.), 1968. Memories and Legacies of a Global Revolt. Washington, EE. UU.: German Historical Institute, 2009.

Gil Zúñiga, José Daniel. «Un mito de la sociedad costarricense: el culto a la Virgen de los Ángeles (1824-1935)». Revista de Historia, n. ${ }^{\circ} 11$ (julio-diciembre, 1985): 47-129. https://www.revistas.una.ac.cr/index.php/ historia/article/view/3184.

Gillis, Chester. Political Papacy: John Paul II, Benedict XVI, and Their Influence. Nueva York, EE. UU.: Routledge, 2006.

Goic, Alejandro. «Opción por los jóvenes: las visiones de Medellín a Puebla. Visiones de la iglesia hoy». En: La juventud latinoamericana en los procesos de globalización. Opción por los jóvenes, (ed.) Peter Hunermann y Margit Eckholt. Buenos Aires, Argentina: FLACSO, 1998.

Gould, Jeffrey. Desencuentros y desafios: ensayos sobre la historia contemporánea. San José, Costa Rica: CIHAC, 2016.

«Solidarity Under Siege: The Latin American Left, 1968». The American Historical Review, 114, n. ${ }^{\circ} 2$ (2009): 348-375. www.jstor.org/ stable/30223783.

Gutiérrez, Rafael y Juan Vicente Córdoba. «Puebla: la opción por los jóvenes». Theologica Xaveriana, . $^{\circ} 52$ (1979): 355-359. Disponible en: https://revistas.javeriana.edu.co/index.php/teoxaveriana/article/view/26357/22285.

Hayes, Michael y Gerald O'Collins, The legacy of John Paul II. Nueva York, EE. UU.: Continuum International Publishing Group, 2008.

Hopkins, Michael. «Continuing Debate and New Approaches in Cold War History». The Historical Journal, 50, n. ${ }^{\circ} 4$ (2007): 913-934. https://doi. org/10.1017/S0018246X07006437.

Instituto Nacional de Estadística y Censos. Estimaciones y proyecciones de población por sexo y edad 1950-2050. San José, Costa Rica: Instituto Nacional de Estadística y Censos/Centro Centroamericano de Población, 2013.

Jaén España, Adrián. Movimientos sociales y solidaridad política: la participación de la izquierda costarricense en la Revolución Sandinista. Tesis 
de Maestría en Ciencias Sociales, Facultad Latinoamericana de Ciencias Sociales, 2013.

Juan Pablo II. «Alocución del papa Juan Pablo II. A los jóvenes en la Basílica de San Pedro». Vatican, 10 de enero de 1979.

«Discurso del Santo Padre Juan Pablo II en la inauguración de la III Conferencia General del Episcopado Latinoamericano». Vatican, 28 de enero de 1979.

- «Encuentro del Santo Padre Juan Pablo II con los jóvenes en la Basílica Vaticana». Vatican, 8 de febrero de 1979.

- «Carta del Santo Padre Juan Pablo II a los participantes en el encuentro celebrado en el Santuario de Guadalupe». Vatican, 15 de febrero de 1979.

—. «Discurso del Santo Padre Juan Pablo II a los jóvenes del movimiento 'Comunión y Liberación'». Vatican, 31 de marzo de 1979.

—. «Discurso del Santo Padre Juan Pablo II a más de seis mil estudiantes universitarios procedentes de todo el mundo». Vatican, 10 de abril de 1979.

—. «Discurso del Santo Padre Juan Pablo II a los muchachos de la Acción Católica Italiana». Vatican, 26 de mayo de 1979.

—. «Peregrinación apostólica a Polonia. Santa misa para la juventud universitaria: homilía de su Santidad Juan Pablo II». Vatican, 3 de junio de 1979. . «Peregrinación apostólica a Polonia. Discurso del papa Juan Pablo II a los jóvenes universitarios». Vatican, 8 de junio de 1979.

«Viaje apostólico a los Estados Unidos de América. Discurso del Santo Padre Juan Pablo II a los estudiantes en el Madison Square Garden». Vatican, 3 de octubre de 1979.

- «Viaje apostólico a los Estados Unidos de América. Discurso del Santo Padre Juan Pablo II a los estudiantes de la Universidad Católica». Vatican, 7 de octubre de 1979.

—. «Visita pastoral a Umbría. Encuentro del Santo Padre Juan Pablo II con los jóvenes». Vatican, 23 de marzo de 1980.

—. «Discurso del Santo Padre Juan Pablo II a una peregrinación de universitarios franceses». Vatican, 5 de abril de 1980.

—. «Discurso del Santo Padre Juan Pablo II a los Consejos Directivo y General del Centro de Iniciativa Juvenil». Vatican, 29 de abril de 1980.

—. «Viaje apostólico a África. Misa para los estudiantes de Costa de Marfil. Homilía del Santo Padre Juan Pablo II». Vatican, 11 de mayo de 1980.

. «Santa misa para el Movimiento GEN -Generación Nueva-. Homilía del Santo Padre Juan Pablo II». Vatican, 18 de mayo de 1980.

- «Viaje apostólico a París y Lisieux. Discurso del Santo Padre Juan Pablo II a los jóvenes reunidos en el Parque de los Príncipes». Vatican, 1 de junio de 1980 . 
—. «Viaje apostólico a Brasil. Homilía del Santo Padre Juan Pablo II durante la misa para los jóvenes». Vatican, 1 de julio de 1980.

«Viaje apostólico a la República Federal de Alemania. Misa para los jóvenes. Homilía del Santo Padre Juan Pablo II». Vatican, 19 de noviembre de 1980.

«Viaje apostólico a América Central. Discurso del Santo Padre Juan Pablo II a los jóvenes». Vatican, 3 de marzo de 1983.

. «Discurso del papa a los jóvenes en el Estadio Nacional». L'Observatore Romano, mayo de 1983, 15 y 16.

—. «Mensaje de su Santidad Juan Pablo II para la celebración de la XVIII Jornada Mundial de la Paz». Vatican, 1 de enero de 1985.

—. «Carta apostólica Dilecti Amici del papa Juan Pablo II a los jóvenes y a las jóvenes del mundo con ocasión del Año Internacional de la Juventud». Vatican, 31 de marzo de 1985.

—_. «La paz y los jóvenes caminan juntos: Mensaje de su Santidad Juan Pablo II para la celebración de la XVIII Jornada Mundial de la Paz». Vatican, 1 de enero de 1985.

«Primera Jornada Mundial de la Juventud. Homilía del Santo Padre Juan Pablo II». Vatican, 23 de marzo de 1986.

«Primera Jornada Mundial de la Juventud». Vatican, 23 de marzo de 1986. Historia de mi vida. Madrid, España: Editorial Encuentro, 2015.

Koselleck, Reinhart. Futuro pasado. Para una semántica de los tiempos históricos. Barcelona, España: Paidós, 1993.

Kengor, Paul. A Pope and a President: John Paul II, Ronald Reagan, and the Extraordinary Untold Story of the 20th Century. Wilmington: Intercollegiate Studies Institute, 2017.

Kengor, Paul y Robert Orlando. The Divine Plan: John Paul II, Ronald Reagan, and the Dramatic End of the Cold War. Wilmington: Intercollegiate Studies Institute, 2019.

Kruijt, Dirk. Guerrilla: guerra y paz en Centroamérica. Ciudad de Guatemala: F\&G Editores, 2009.

La Nación. «Obispos comunicaron a Monge visita del Papa», 10 de diciembre de 1982, 1A-2A.

La Nación. «Hoy llega el Santo Padre», 2 de marzo de 1983, 1A-17A.

La Nación. «El Papa llega con mensaje de paz», 3 de marzo de 1983, 1A-19A.

La Nación. «Histórico encuentro de fe», 4 de marzo de 1983, 1A-13A.

La Nación. «Papa invita a jóvenes a luchar contra el odio y la violencia», 4 de marzo de 1983, 4A.

León Sáenz, Luis. «El potencial para la evangelización es la juventud». Eco Católico, 16 de junio de 1986, 3. 
L'Observatore Romano. «Itinerario apostólico de Juan Pablo II por América Central, 2-10 marzo 1983», mayo de 1983, 4 y 5.

Lutte, Gérard. «La Revolución de los muchachos: los jóvenes en la Nicaragua Sandinista». En: La construcción histórica de la juventud en América Latina. Bohemios, rockanroleros \& revolucionarios, (ed.) Yanko González y Carles Feixa. Santiago, Chile: Editorial Cuartopropio, 2013.

Margulis, Mario (ed.). La juventud es más que una palabra. Buenos Aires, Argentina: Editorial Biblos, 2008.

Martin, Malachi. The Keys of This Blood: Pope John Paul II Versus Russia and the West for Control of the New World Order. Nueva York, EE. UU.: A Touchstone Book, 1991.

Mensajero Eclesial. «Nuestra Arquidiócesis se organiza en su Pastoral Juvenil», abril de 1971, 3-4.

Mensajero del Clero. «Proyecto Pastoral basado en el V Sínodo Arquidiocesano», abril de 1986, 6-19.

Molina Jiménez, Iván. «Catolicismo y comunismo en Costa Rica (1931-1940)». Desacatos, n. $^{\circ} 22$ (2006): 157-172. http://desacatos.ciesas.edu.mx/index. $\mathrm{php} /$ Desacatos/article/view/625.

- «La composición social de los estudiantes universitarios en América Latina. El caso de la Universidad de Costa Rica (1950-1973)». Revista de Historia de América, n. ${ }^{\circ} 151$ (2015): 57-90. https://revistasipgh.org/index. $\mathrm{php} / \mathrm{rehiam} /$ article/view/393.

—_ La educación en Costa Rica de la época colonial al presente. San José, Costa Rica: Editoriales Universitarias Públicas Costarricenses, 2016.

—. «Párvulos guerrilleros. Las huelgas estudiantiles de 1980 en el Instituto Tecnológico de Costa Rica». Diálogos. Revista Electrónica de Historia, 19, n. 2 (2018): 1-35. https://doi.org/10.15517/dre.v19i2.32283.

- Huelgas democratizadoras: la rebelión estudiantil en el Instituto Tecnológico de Costa Rica (1980-1982). San José, Costa Rica: CIHAC; Editoriales Universitarias Públicas Costarricenses, 2019.

—. «La huelga estudiantil de 1982 y la democratización del Instituto Tecnológico de Costa Rica». Diálogos, 23, n. ${ }^{\circ}$ 1, (2019): 130-150. https://doi. org/10.4025/dialogos.v23i1.45253.

Monge Solano, Gustavo Adolfo. «El joven y su obligación con la Iglesia». Eco Católico, 1 de junio de 1986, 11.

Montes, Tony. «Gracias jóvenes ciudadanos». Eco Católico, 3 de julio de 1983, 5.

Muñoz, Fabio. «Las convivencias juveniles». Contrapunto, 16 de diciembre de 1982, 7.

Muñoz, Fabio. «Hablan sacerdotes y jóvenes creyentes: Dios con los jóvenes». Contrapunto, 1 de agosto de 1983, 14-15. 
Muñoz Mora, Fernando. «Toda pastoral juvenil es vocacional». Eco Católico, 5 de mayo de 1985, 6.

Neirotti, Nerio y Matías Mattalini. «La Iglesia católica en América Latina». En: Atlas histórico de América Latina y el Caribe: aportes para la descolonización pedagógica y cultural. Tomo III: América Latina en el siglo XXI: la edad de los derechos en la patria de la justicia, (ed.) Ana Jaramillo. Lanús: Editorial de la Universidad Nacional de Lanús, 2017.

Organización de las Naciones Unidas. «Resolución 40/14. Año Internacional de la Juventud: Participación, Desarrollo y Paz». United Nations, 15 de noviembre de 1985, 205-206. https://www.un.org/es/events/youthday/.

Orlandis Rovira, José. «Consideraciones sobre la evolución estadística de la Iglesia en el último cuarto del siglo XX». Anuario de Historia de la Iglesia, n. ${ }^{\circ} 12$ (2003): 181-200. http://hdl.handle.net/10171/9355.

Ornatowski, Cezar M. «Rhetoric of Pope John Paul II's Visits to Poland, 19791999». En: The rhetoric of Pope John Paul II, (ed.) Joseph Blaney y Joseph Zompetti. Nueva York, EE. UU.: Lexington Books, 2009.

Pablo VI. «Mensaje del Concilio Vaticano II a los jóvenes». Vatican, 7 de diciembre de 1965.

——. «Peregrinación apostólica a Bogotá. Inauguración de la II Asamblea General de los obispos de América Latina. Homilía del Santo Padre Pablo VI». Vatican, 24 de agosto de 1968.

Pensado, Jaime. «El Movimiento Estudiantil Profesional (MEP): Una mirada a la radicalización de la juventud católica mexicana durante la Guerra Fría». Mexican Studies, 31, n. ${ }^{\circ} 1$ (2015): 156-192. https://doi.org/10.1525/ msem.2015.31.1.156.

Pérez Islas, José Antonio. «Juventud: un concepto en disputa». En: Teorías sobre la juventud. Las miradas de los clásicos, (coord.) José Antonio Pérez Islas, Mónica Valdéz González y María Herlinda Suárez Zozaya. México, D.F.: Universidad Nacional Autónoma de México, 2008.

Pérez Islas, José Antonio, Mónica Valdéz González y María Herlinda Suárez Zozaya (coord.). Teorías sobre la juventud. Las miradas de los clásicos. México, D.F.: Universidad Nacional Autónoma de México, 2008.

Philip J. Williams. The Catholic Church and Politics in Nicaragua and Costa Rica. Nueva York, EE. UU.: Palgrave Macmillan, 1989.

Picado Gatjens, Miguel. La Iglesia costarricense: entre Dios y el César. San José, Costa Rica: Departamento Ecuménico de Investigaciones, 1989.

_- La Iglesia costarricense entre el Pueblo y el Estado: de 1949 a nuestros dias. San José: Ediciones Guayacán, 1990.

Secretos de un acuerdo: Monseñor Sanabria y Manuel Mora, junio de 1943. San José, Costa Rica: EUNED, 2013. 
Pieper Mooney, Jadwiga E. y Fabio Lanza (ed.). De-centering Cold War History: Local and Global Change. Londres: Routledge, 2012.

Ramírez, Alberto. «La Conferencia de Medellín y la Teología de la Esperanza». Cuestiones Teológicas, 35, n. ${ }^{\circ} 84$ (2008): 235-254. https://revistas.upb. edu.co/index.php/cuestiones/article/view/44.

Ramírez Mercado, Sergio. Adiós muchachos. México, D.F.: Alfaguara, 2007.

Revilla Castro, Juan Carlos. «La construcción discursiva de la juventud: lo general y lo particular». Papers, n. ${ }^{\circ}$ 63-64 (2001): 103-122. http://dx.doi. org/10.5565/rev/papers/v63n0.1209.

Rey Tristán, Eduardo. «Guerrilla o terrorismo. El debate en torno a la caracterización de algunas organizaciones revolucionarias a partir del caso de La Familia». Diálogos. Revista Electrónica de Historia, 9, n. ${ }^{\circ}$ especial (2008): 4168-4188.

Richard, Pablo y Guillermo Meléndez. La Iglesia de los pobres en América Central. San José, Costa Rica: Departamento Ecuménico de Investigaciones, 1982.

Rodríguez Blanco, Óscar. «La paz y los jóvenes caminan juntos». Eco Católico, 24 de febrero de 1985, 14.

Rodríguez, Óscar. «Año Internacional de la Juventud». Eco Católico, 11 de noviembre de 1984, 13.

Rodríguez Quirós, Carlos. «Decreto de Integración del Equipo de Pastoral Orgánica de Juventudes y de Encuentros de Promoción Juvenil». Mensajero Eclesial, marzo de 1971, 7 y 14.

Rojas, Rafael. Historia mínima de la Revolución cubana. México, D.F.: El Colegio de México, 2015.

Sancho, Eugenia. «Sencillez, candor, magnetismo... el carisma de Juan Pablo II». Contrapunto, 16 de marzo de 1983, 10.

Sandí Morales, José Aurelio. «La participación de la Iglesia católica en el control del espacio en medio de la creación de un país llamado Costa Rica, 18501920». Revista de Historia, n. ${ }^{\circ}$ 63-64 (enero-diciembre, 2011): 53-99. https://www.revistas.una.ac.cr/index.php/historia/article/view/4583.

Souto Kustrín, Sandra. «"El mundo ha llegado a ser consciente de su juventud como nunca antes". Juventud y movilización política en la Europa de entreguerras». Mélanges de la Casa de Velázquez, 34, n. ${ }^{\circ}$ (2004), 179-215. https://journals.openedition.org/mcv/1190.

—. «Juventud, teoría e historia: la formación de un sujeto social y de un objeto de anaálisis». Historia Actual Online, n. ${ }^{\circ} 13$ (2007): 171-192. http://hdl. handle.net/10261/162771.

Swift, John. The palgrave concise historical atlas of the Cold War. Nueva York, EE. UU.: Springer, 2003. 
Torres Rivas, Edelberto (ed.). Escépticos, rebeldes, narcisos: seis estudios sobre la juventud. San José, Costa Rica: FLACSO, 1989.

Vargas Arias, Claudio. El liberalismo, la Iglesia y el Estado en Costa Rica. San José, Costa Rica: Ediciones Guayacán, 1987.

Velázquez Bonilla, Carmela. «La Diócesis de Nicaragua y Costa Rica: su conformación y sus conflictos, 1531-1850». Revista de Historia, n. ${ }^{\circ} 49-50$ (enero-diciembre, 2004): 245-286. https://www.revistas.una.ac.cr/index. $\mathrm{php} / \mathrm{historia/article/view/1788.}$

Weigel, George. Witness to Hope: The Biography of Pope John Paul II. Nueva York, EE. UU.: Harper Perennial, 2005.

Wilhelm Schäfer, Heinrich. «Transformaciones de la praxis religiosa de actores no-católicos en relación con la violencia. Guatemala y Nicaragua, 1980 a 2015». En: ¿Cuándo pasará el temblor?: Crisis, violencia y paz en la América Latina Contemporánea, (ed.) David Díaz Arias y Christine Hatzky. San José, Costa Rica: CIHAC, 2019.

Wilhelm Schäfer, Heinrich. Protestantismo y crisis social en América Central. San José, Costa Rica: Departamento Ecuménico de Investigaciones, 1992.

Zolov, Eric. «Latin America in the Global Sixties». The Americas, 70, n. ${ }^{\circ} 3$ (2014): 394-362. https://doi.org/10.1017/S0003161500003953. 
